\title{
Anterograde Axonal Transport in Neuronal Homeostasis and Disease
}

\author{
Laurent Guillaud*, Sara Emad El-Agamy, Miki Otsuki and Marco Terenzio* \\ Molecular Neuroscience Unit, Okinawa Institute of Science and Technology Graduate University, Okinawa, Japan
}

OPEN ACCESS

Edited by:

Santiago Quiroga,

National University of Cordoba,

Argentina

Reviewed by:

Peter Baas,

Drexel University, United States Stephanie L. Gupton,

University of North Carolina at Chapel Hill, United States

Gerardo Morfini,

University of Illinois at Chicago,

United States

*Correspondence:

Laurent Guillaud

laurent.guillaud@oist.jp

Marco Terenzio

marco.terenzio@oist.jp

Received: 27 April 2020

Accepted: 26 August 2020

Published: 18 September 2020

Citation:

Guillaud L, El-Agamy SE, Otsuki M and Terenzio M (2020) Anterograde Axonal Transport in Neuronal Homeostasis and Disease.

Front. Mol. Neurosci. 13:556175. doi: 10.3389/fnmol.2020.556175
Neurons are highly polarized cells with an elongated axon that extends far away from the cell body. To maintain their homeostasis, neurons rely extensively on axonal transport of membranous organelles and other molecular complexes. Axonal transport allows for spatio-temporal activation and modulation of numerous molecular cascades, thus playing a central role in the establishment of neuronal polarity, axonal growth and stabilization, and synapses formation. Anterograde and retrograde axonal transport are supported by various molecular motors, such as kinesins and dynein, and a complex microtubule network. In this review article, we will primarily discuss the molecular mechanisms underlying anterograde axonal transport and its role in neuronal development and maturation, including the establishment of functional synaptic connections. We will then provide an overview of the molecular and cellular perturbations that affect axonal transport and are often associated with axonal degeneration. Lastly, we will relate our current understanding of the role of axonal trafficking concerning anterograde trafficking of mRNA and its involvement in the maintenance of the axonal compartment and disease.

Keywords: kinesin, intracellular transport, axon growth, synaptogenesis, neurodegeneration, local translation, liquid phase separation

\section{INTRODUCTION}

From the discovery of kinesin-1 (Vale et al., 1985) and cytoplasmic dynein (Paschal et al., 1987) in the late 20th century and their initial characterization as anterograde and retrograde motors, respectively (Hirokawa et al., 1990, 1991), substantial effort has been made to decipher their role in neuronal development, connectivity, and synaptogenesis. Since neurons are highly polarized cells with a heavily arborized dendritic network and an elongated axon that can extend over a meter away from their soma, they rely extensively on efficient intracellular transport for the targeting and sorting of proteins and organelles from the soma to their neurite network, where the transfer of information between presynaptic neurons and postsynaptic cells occurs (Südhof, 2018). The somatodendritic and axonal domains have distinct traffic properties and show selectivity towards specific populations of carrier vesicles (Farías et al., 2015). Indeed most somatodendritic vesicles fail to enter the axonal compartment at the level of the axon initial segment (AIS), a highly ordered specialized region of the proximal axon, which acts as a barrier to the diffusion of proteins and lipids between the two compartments 
(Farías et al., 2015). Long-range trafficking is largely performed by several motor proteins of the kinesin superfamily and cytoplasmic dynein (Hirokawa and Tanaka, 2015; Reck-Peterson et al., 2018). Kinesins mostly deliver their cargoes toward the periphery, while dynein moves in the opposite direction toward the center of the cell (Figure 1A).

Intracellular transport is a fundamental mechanism underlying a variety of neuronal processes, including the establishment of cell polarity, axon growth or regeneration, synaptogenesis, and synaptic transmission and plasticity. Thus, axonal transport has been extensively studied in the past decades. Although the biochemical mechanisms of molecular motors-based transport are well understood, many of the regulatory pathways remain poorly understood, particularly in connection with pathology. It is not surprising to observe that axonal transport perturbations are often associated with severe neurodegenerative pathologies, though whether they are the direct cause or the result of these pathologies remains an open question. Indeed, the nervous system can be affected by a variety of adult-onset neurodegenerative diseases, which are characterized by early synaptic deficit and neurite dysfunction, a phenomenon referred to as "dying back" (Brady and Morfini, 2017). Thus, axonal homeostasis is often affected well before degenerative symptoms can manifest themselves at the level of the neuronal soma. Several pieces of evidence have shown a correlation between mutation of components of the transport machinery (microtubule, molecular motors, and molecular adaptors) and the genesis of neurodevelopmental and neurodegenerative diseases (Maday et al., 2014; Beijer et al., 2019; Sleigh et al., 2019). Also, impairment of axonal transport has been reported in a multitude of neurological disorders that are not directly linked to mutations of proteins belonging to the transport machinery (Sleigh et al., 2019).

Some cargoes are transported along axons anterogradely, some retrogradely and some bidirectionally. Synaptic vesicles, neurofilaments (NFs), and cytosolic proteins are examples of cargoes transported in anterograde fashion while signaling endosomes, autophagosomes, and injury signals are transported retrogradely (Olenick and Holzbaur, 2019). Mitochondria, certain endosomal populations, lysosomes, and mRNAs are transported in a bi-directional manner (Olenick and Holzbaur, 2019). Adaptor proteins selectively recruit molecular motors to specific cargoes targeting them to different transport pathways, which are often interdependent if not convergent (Jean and Kiger, 2012). Interestingly, the aforementioned routes of cargo transport in axons are also taken advantage of by external pathogens such as viruses (Taylor and Enquist, 2015). Even though the two routes are often interdependent as previously mentioned, we will concentrate on the mechanisms of anterograde axonal transport of membrane-bound and membrane-less organelles in neuronal physiology, focusing on several key aspects of axonal growth and synaptogenesis, and other cellular mechanisms such as local mRNA translation and liquid phase separation (LPS) that are likely to be fundamental actors in the regulation of axonal homeostasis and functions. We will also address the links between axonal transport dysfunctions and neurodegeneration, focusing on few neurodegenerative diseases as an example of how defects in anterograde axonal transport can result in neurodegeneration. Though outside of the scope of this review, an extensive wealth of evidence links neurodegeneration and retrograde axonal transport. For extensive coverage of these pathologies and their link to intracellular transport please refer to these comprehensive reviews (Schiavo et al., 2013; De Vos and Hafezparast, 2017; Beijer et al., 2019). We will also briefly discuss the contribution of the cytoskeleton as a necessary platform to facilitate long-range trafficking of mitochondria, which, while moving bidirectionally, need to be addressed as they represent the main source of energy for intracellular transport.

\section{CYTOSKELETAL ELEMENTS OF AXONAL TRANSPORT}

Due to their extremely polarized morphology and their status of postmitotic cells, neurons need to maintain a solid structural cytoskeleton, which is composed of microtubules (MTs), intermediate filaments, and actin filaments. This structure is fundamental to neuronal function and its disruption is associated with neurodegeneration (Beijer et al., 2019).

Active axonal transport of proteins and membranous organelles takes place along MTs (Weisenberg, 1972; Desai and Mitchison, 1997), upon which molecular motors of the kinesin superfamily (Vale et al., 1985; Hirokawa et al., 1989; Lawrence et al., 2004), and cytoplasmic dynein (Paschal and Vallee, 1987; Reck-Peterson et al., 2018) are loaded (Figure 1A). Axonal MTs are longitudinally aligned with their growing plus-end directed towards the axon tip; a large number of kinesins are moving from MT minus to plus-end in a processive manner, while dynein goes in the opposite direction (Howard et al., 1989; Wang et al., 2015). In addition to MTs, NFs are the most abundant cytoskeletal component in axons and control axonal diameter (Grant and Pant, 2000). NFs are formed by neurofilament light (NF-L), medium (NF-M), and heavy (NF-H) chains, apart from the peripheral nervous system, where they contain peripherin as well (Grant and Pant, 2000). While kinesins and dynein are MT associated motors, a third family of molecular motors, myosins, is reliant on actin filaments (Xiao et al., 2016; Beijer et al., 2019). Interestingly, Myosin Va can couple MT and Actin filament-based transport via its interaction with Kinesin heavy chain and NF-L, thus helping to regulate the cargo distribution across the cytoskeleton (Cao et al., 2004; Rao et al., 2011).

\section{Neuropathologies Related to Cytoskeletal Defects}

In light of their essential structural function in axons, NFs are critical for axonal transport. NF-L in particular has been shown to regulate NF integrity and their axonal transport (Yates et al., 2009). Not surprisingly, alteration of cytoskeletal elements has been described in several neurodegenerative diseases, where either cytoskeletal proteins or their adaptor/regulators are mutated (Beijer et al., 2019). Perhaps one of the best examples of such pathologies is the Charcot-Marie-Tooth disease (CMT), which is the most common hereditary neuropathy, characterized by distal muscular atrophy and sensory loss 
A

Dynein

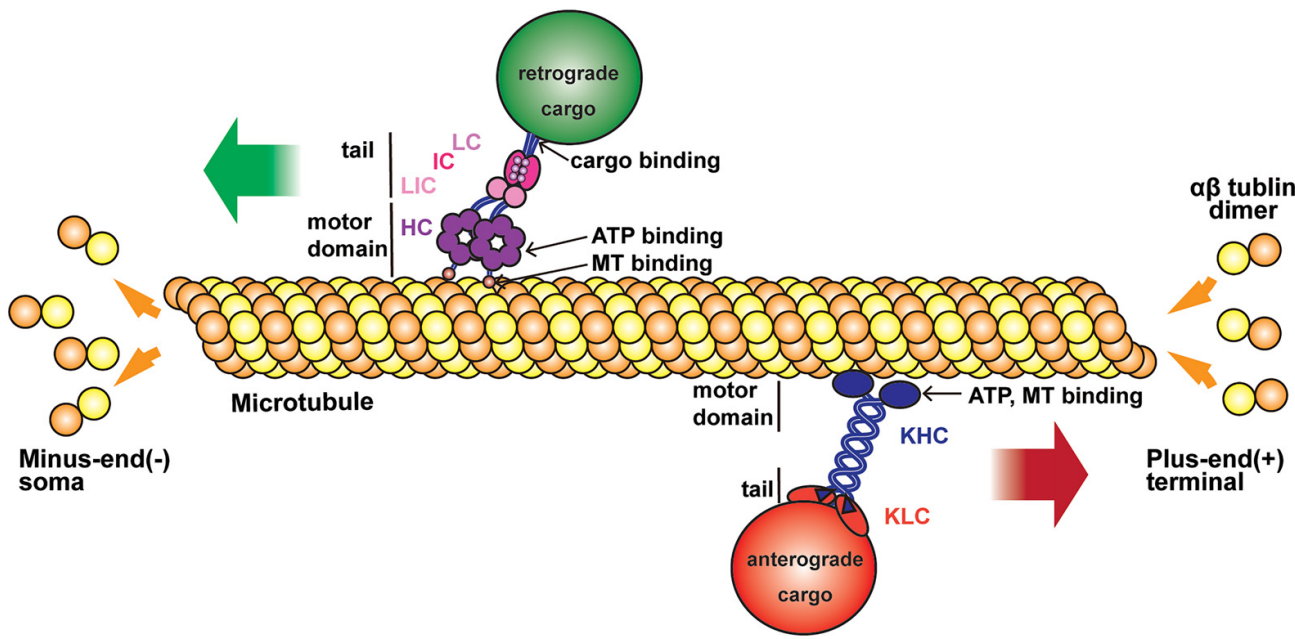

Kinesin

B
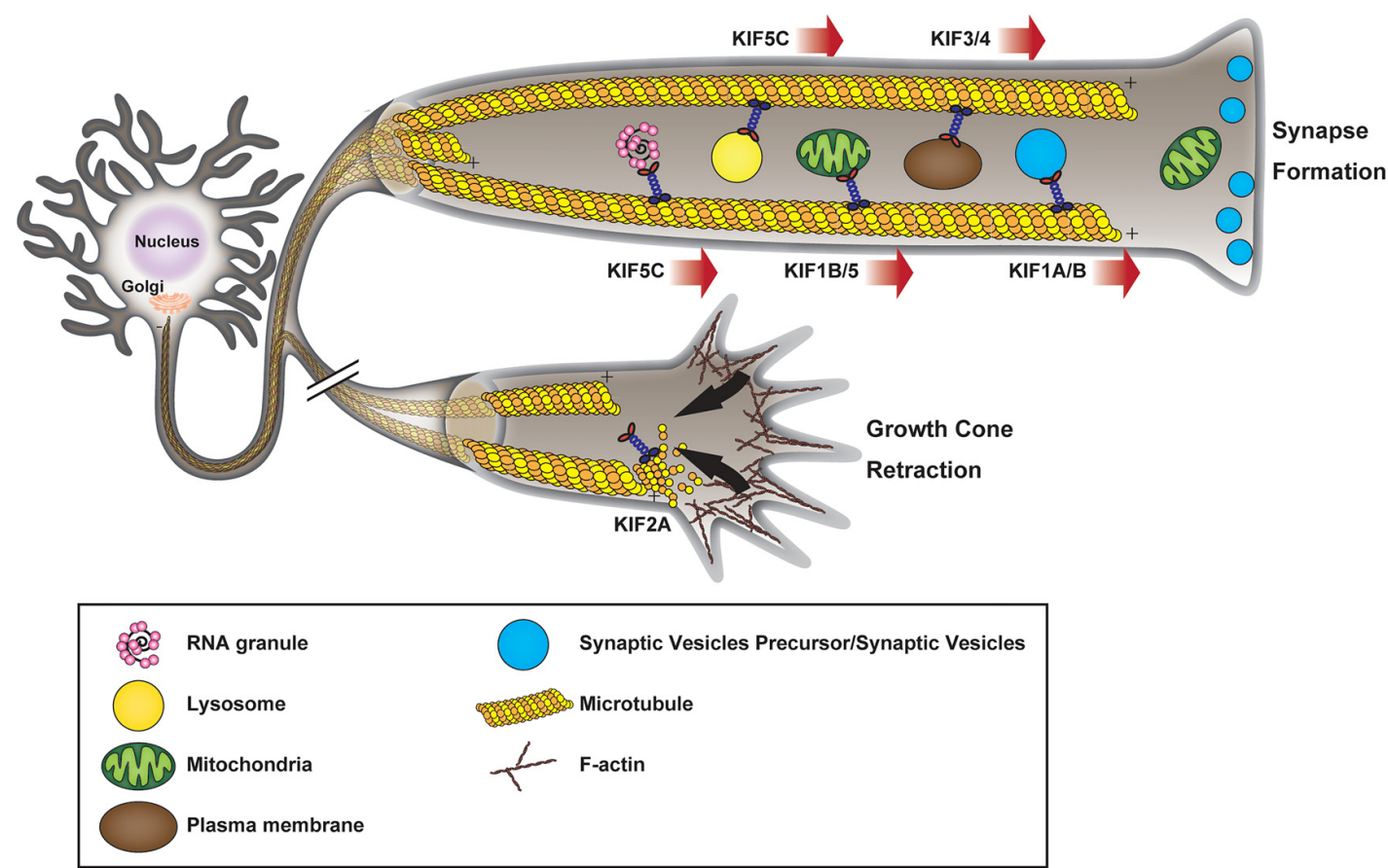

FIGURE 1 | (A) Microtubule (MT)-based transport machinery. Schematic representation showing how different molecular motors move along MTs toward MT plus-end (kinesins) or MT minus-end (dynein). Kinesins and dyneins motor domain bind to MT through their globular head domains which hydrolyze ATP during movement. Anterograde or retrograde cargoes bind to the tail domain of the motor either directly or through light/intermediate chains or adaptors. (B) Kinesin-mediated anterograde transport during axon elongation and synaptogenesis. Anterograde microtubule-dependent movements of membranous organelles and RNA granules are supported by various plus-end-directed kinesin motors. Organelles such as mitochondria, vesicles, RNA are transported from the soma toward axon tip during axonal growth and synapse formation. In the absence of motor activity, some kinesins also contribute to MT depolymerization during growth cone retraction. 
(Züchner and Vance, 2006). CMT subtype E (CMT2E) is associated with mutations affecting the integrity of the neuronal cytoskeleton, where mutant NF-L disrupts neurofilament assembly and axonal transport (Jordanova et al., 2003; Lancaster et al., 2018), which in turn perturbs mitochondrial distribution, determining their accumulation within cell bodies and proximal axons (Brownlees et al., 2002). A recessive nonsense mutation was identified in an early-onset CMT patient, which causes a nearly total loss of NF-L mRNA and the subsequent depletion of NF-L protein in patient's cultured neurons (Sainio et al., 2018). Mutations of different functional NF-L domains were also shown to have different effects on filament assembly, with the Q333P mutation leading to reduced NF dimerization (Gentil et al., 2013), while the $P 8 L$ mutation of the head domain affects NF-L phosphorylation, resulting in the destabilization of NF complexes (Brownlees et al., 2002).

NF-H mutations have also been implicated in CMT. A frameshift variant of NF-H leading to the translation of the 3'UTR has been described in families affected by CMT (Rebelo et al., 2016) and shown to result in prominent intracellular protein aggregation, affecting motor neuron viability (Rebelo et al., 2016). These aggregates are recognized by the autophagic pathway, triggering caspase 3 activation, and apoptosis (Jacquier et al., 2017).

While CMT has been associated with direct mutations of cytoskeletal proteins, disruption of MTs can also occur indirectly as a consequence of the mutation of partner proteins that act as MT adaptors and/or interactors. Indeed, mutations of the small heat shock protein HSPB1 and HSPB8 cause distal hereditary motor neuropathy (dHMN) and CMT, and are associated with cytoskeletal abnormality (d'Ydewalle et al., 2011; Irobi et al., 2012; Bouhy et al., 2018). S135F and P182L mutations of HSPB1 were shown to decrease acetylated $\alpha$-tubulin abundance, severely affecting axonal transport (d'Ydewalle et al., 2011). Furthermore, HSPB1-P182L mutation affects the assembly and transport of NFs, leading to the formation of intracellular aggregates, which include NF-M (Ackerley et al., 2006).

Though the list of neuronal pathologies displaying cytoskeletal defects is constantly growing, we would like to discuss briefly two additional diseases, as an example of pathologies where alteration of cytoskeletal elements is a hallmark of the disease.

Hereditary spastic paraplegia (HSP) is a pathology that leads to axonal degeneration in the corticospinal tracts and, to a lesser extent, in the dorsal column fibers (Shribman et al., 2019). HSP displays perhaps one of the strongest examples of the correlation between defective axonal transport and neurodegeneration (Dion et al., 2009) since most of the genes implicated in HSP encode for proteins that are engaged in intracellular trafficking. The most prevalent form of autosomal dominant HSP stems from point mutation or deletion in the SPG4 gene encoding spastin, a protein involved in MT severing (Roll-Mecak and Vale, 2008). Spastin deletion in mice resulted in defective axonal trafficking, manifested as the accumulation of organelles and NF into focal swellings found exclusively in axonal regions that exhibited fast transition between MT stabilization states (Tarrade et al., 2006). Furthermore, spastin mutants fail to sever
MTs, leading to the mislocalization of intracellular organelles (McDermott et al., 2003). A spastin isoform has also been shown to significantly impair fast axonal transport (Solowska et al., 2008) via the activation of kinases and phosphatases that play a major role in regulating motor proteins binding to MT and cargoes (Leo et al., 2017). Alteration of MT bundling could also contribute to the disease since spastin was described to be able to bundle MTs in vitro (Salinas et al., 2007).

Interestingly, NFs are used as a clinical biomarker in a sporadic and clinical trial for several neurodegenerative diseases, including ALS (Loeffler et al., 2020). Indeed, accumulation of intermediate filament proteins including peripherin is a common pathological feature in both sporadic and familial ALS (Figlewicz et al., 1994; Tomkins et al., 1998; Al-Chalabi et al., 1999; Gros-Louis et al., 2004). NF-H side arm phosphorylation has been reported to slow down the axonal transport of NF by increasing its pausing (Ackerley et al., 2003). Alteration in the stoichiometry of NF subunits has been linked to ALS, while NF side arm phosphorylation is induced by excitotoxic glutamatemediated activation of JNK, p38 and CDK-p25 kinase (Bajaj and Miller, 1997; Ackerley et al., 2000, 2004). Overexpression of NF-H, NF-L, or peripherin in mice recapitulated the disease pathological features (Collard et al., 1995; Millecamps et al., 2006). Also, TAR DNA-binding protein 43 (TDP-43), one of the key proteins identified in ALS patients neuronal inclusions, can interact with the neuronal cytoskeleton (reviewed in Oberstadt et al., 2018; Hergesheimer et al., 2019), has been shown to alter the stability of NF-L mRNA when mutated (Volkening et al., 2009; Prasad et al., 2019) and impair trafficking and anterograde transport of messenger ribonucleoprotein (mRNP) granules (Alami et al., 2014). Furthermore, loss of function mutations in tubulin alpha 4A protein (TUBA4A) that disrupt MT stability and diminish their repolymerization have been documented in familial ALS cases (Smith et al., 2014), though their impact on axonal trafficking has not been fully elucidated yet. However, since MT stability is central to axonal trafficking, it is likely to be detrimental.

\section{MOLECULAR DRIVERS OF ANTEROGRADE AXONAL TRANSPORT AND THEIR ROLE IN NEURODEGENERATIVE DISEASES}

\section{The Kinesin Family of Molecular Motors}

A total of 45 genes organized in 15 families are associated with kinesins (also called KIFs) in the human genome (Miki et al., 2001; Lawrence et al., 2004; Hirokawa and Tanaka, 2015; Nabb et al., 2020; Table 1). Kinesin-1, kinesin-2, kinesin-3 and to a lesser extent kinesin-4 subfamily members are implicated in both fast $(50-400 \mathrm{~mm} /$ day) and slow (less than $8 \mathrm{~mm} /$ day) axonal transport (Maday et al., 2014). Fast axonal transport traffics membranous organelles, proteins, and mRNA granules, while slow axonal transport moves MT/NF fragments or other cytosolic proteins necessary for the establishment of neuronal polarity, axon growth and synapse formation (Hirokawa and Tanaka, 2015; Nabb et al., 2020). 
TABLE 1 | Kinesin superfamily classification.

\begin{tabular}{|c|c|c|c|}
\hline Kinesin family & KIFs & $\begin{array}{l}\text { Reported axonal } \\
\text { localization }\end{array}$ & References \\
\hline Kinesin-1 & KIF5A, KIF5B, KIF5C & KIF5A, KIF5B, KIF5C & $\begin{array}{l}\text { (Xia et al., 2003; Colin et al., 2008; Ma et al., 2009; Nakajima et al., } \\
\text { 2012; Su et al., 2013; Campbell et al., 2014; Xiao et al., 2016) }\end{array}$ \\
\hline Kinesin-2 & KIF3A, KIF3B, KIF3C, KIF17 & KIF3A, KIF3B, KIF3C & Takeda et al. (2000) and Nishimura T. et al. (2004) \\
\hline Kinesin-3 & $\begin{array}{l}\text { KIF1A, KIF1B, KIF1C, KIF13A, KIF13B, } \\
\text { KIF14, KIF16A, KIF16B }\end{array}$ & KIF1A, KIF1B, KIF3B & $\begin{array}{l}\text { Okada et al. (1995), Yonekawa et al. (1998), Miller et al. (2005), } \\
\text { Horiguchi et al. (2006), Niwa et al. (2008), Yoshimura et al. (2010), } \\
\text { Lo et al. (2011), Kondo et al. (2012), Bharat et al. (2017), Zhang } \\
\text { et al. (2017) and Stucchi et al. (2018) }\end{array}$ \\
\hline Kinesin-4 & $\begin{array}{l}\text { KIF4A, KIF4B, KIF7, KIF21A, KIF21B, } \\
\text { KIF27 }\end{array}$ & KIF4A, KIF21A, KIF21B & $\begin{array}{l}\text { Sekine et al. (1994), Midorikawa et al. (2006), Bisbal et al. (2009), } \\
\text { Lee et al. (2012), van der Vaart et al. (2013), Heintz et al. (2014) } \\
\text { and Swarnkar et al. (2018) }\end{array}$ \\
\hline Kinesin-5 & KIF11 & KIF11 & Swarnkar et al. (2018) \\
\hline Kinesin-6 & KIF20A, KIF20B, KIF23 & KIF20B, KIF23 & Lin et al. (2012), Sapir et al. (2013) and McNeely et al. (2017) \\
\hline Kinesin-7 & KIF10 & & \\
\hline Kinesin-8 & KIF18A, KIF18B, KIF19 & & \\
\hline Kinesin-9 & KIF6, KIF9 & & \\
\hline Kinesin-10 & KIF22 & KIF22 & Park et al. (2016) \\
\hline Kinesin-11 & KIF26A, KIF26B & KIF26A & Zhou et al. (2009) and Wang et al. (2018) \\
\hline Kinesin-12 & KIF12, KIF15 & & \\
\hline Kinesin-13 & KIF2A, KIF2B, KIF2C, KIF24 & KIF2A & $\begin{array}{l}\text { Morfini et al. (1997), Homma et al. }(2003,2018) \text { and Pfenninger } \\
\text { et al. (2003) }\end{array}$ \\
\hline Kinesin-14 & KIF25, KIFC1, KIFC2, KIFC3 & KIFC1 & Muralidharan and Baas (2019) \\
\hline
\end{tabular}

The members of each family are listed, including KIFs that have been documented in axons (separate columns). References are given for the axonal KIFs.

Plasma membrane proteins generally originated in the rough endoplasmic reticulum at the level of the neuronal soma, must also be delivered peripherally by specialized transport vesicles, and be sorted separately, depending on their axonal or dendritic localization (Bentley and Banker, 2016; Nabb et al., 2020). Kinesin complexes are composed of a globular motor domain, which binds and moves along the MT lattice upon ATP hydrolysis (Hua et al., 1997; Schnitzer and Block, 1997; Kon et al., 2005; Wang et al., 2015), and a tail domain that contributes to the motor auto-inhibition mechanism and the recruitment of various cargoes either directly or through interaction with intermediate scaffolding complexes (Hirokawa et al., 2010). It has been reported that a single cargo could be associated with several motors proteins and the resulting force produced by the ratio between plus-end and minus-end directed motors might determine the final directionality of the movement (Kural et al., 2005; Hendricks et al., 2010), however, only a few cargoes were addressed in this work and it remains unclear whether these findings extend to other cargoes as well. The binding of the cargoes to the motor complex via kinesin light chains in the soma, and their release at their final destination, often depends on phosphorylation/dephosphorylation of the motor (Horiuchi et al., 2007; Guillaud et al., 2008; Verhey and Hammond, 2009).

While the motor domain is highly conserved and well-characterized in its structure and function (Sweeney and Holzbaur, 2018), the tail domain is more variable and less understood (Nabb et al., 2020). Most work regarding the tail domain characterization has been the focus on kinesin-1 (KIF5A/B/C) and kinesin-3 (KIF1A) family members, which are most studied motors responsible for anterograde transport in the axon, and for which a large number of adaptor proteins mediating their binding to a different population of vesicles has been identified (Verhey et al., 2001; Setou et al., 2002; Wang and Schwarz, 2009; Fu and Holzbaur, 2014). Our knowledge of adaptor proteins for other kinesin families is less defined and the complexity of these interactions is enhanced by the number of vesicle populations in neurons and the need for fine sorting compounded by the extreme neuronal morphology. Indeed, selective anterograde transport in axons and dendrites is essential for the maintenance of neuronal function and polarity, as proteins and vesicles move in one of these compartments and are excluded from the other (Nabb et al., 2020). We will address some of the adaptor proteins involved in this sorting in the following sections, but a more extensive and detailed coverage can be found in this review (Nabb et al., 2020).

The regulation of transport initiation is a critical aspect of kinesin's ability to mediate axonal transport. Indeed, free cytosolic kinesin-1 and 3 are blocked in an autoinhibited state and can only bind to MTs after a conformational change made possible by their interaction with their cargo (Guedes-Dias and Holzbaur, 2019). Said binding depends on electrostatic interactions between kinesin and tubulin (Woehlke et al., 1997), and the interaction between motor and MTs seems to be stronger for kinesin 3 compared to kinesin-1 (Okada and Hirokawa, 2000; Atherton et al., 2014; Soppina and Verhey, 2014; Lessard et al., 2019). The nucleotide state of MTs can also influence the binding of kinesin-3, which displays higher affinity for GTP-like MTs (Guedes-Dias et al., 2019), while kinesin-1 preferences are still unclear (Nakata et al., 2011; Li et al., 2017; Guedes-Dias et al., 2019). A well-known example of MAPs, which has been reported to inhibit the binding and motility of kinesin-1 is Tau (Dixit et al., 2008; Kellogg et al., 2018; Monroy et al., 2018). Interestingly, Tau mutations account for approximately $50 \%$ of cases of Frontotemporal Dementia and Parkinsonism linked to chromosome 17 (FTDP-17), which is characterized by progressive dementia with gradual functional decline (Siuda 
et al., 2014; Ikeda et al., 2019). However, a large percentage of familiar FTDP-17 are also associated with concurrent mutation of the progranulin (GRN) gene linked to a similar region on chromosome 17 (Forrest et al., 2018). MAP7 on the other hand facilitates the binding of kinesin-1 to MTs via its interaction with the stalk domain (Monroy et al., 2018; Hooikaas et al., 2019). Said interaction was recently shown to be important for axonal sorting of cargoes, as MAP7D2 isoform preferentially localizes to MTs in the proximal axon region, where it recruits kinesin-1 (Pan et al., 2019).

\section{Kinesin-Based Transport Role in Axonal Growth, Brain Wiring, and Neuronal Development}

After the establishment of neuronal polarity, axonal elongation is sustained by the addition of membranes to neurite growing tips (Figure 1B). Indeed, plasma membrane precursors and vesicles transported by kinesin-driven axonal anterograde transport from the soma toward the growth cone are crucial to axonal development and wiring (Guedes-Dias and Holzbaur, 2019). KIF13B, for example, anterogradely transports PIP3-containing vesicle, regulating the establishment of neuronal polarity (Horiguchi et al., 2006). Knockdown of KIF13B in hippocampal neurons results in an "axonless" phenotype and Par1b/MARK2mediated phosphorylation of KIF13B was shown to mediate axon formation (Yoshimura et al., 2010). In PC12 cells, KIF2 deletion inhibits anterograde transport of membranous vesicles and associated receptors, negatively impacting neurite outgrowth (Morfini et al., 1997). KIF2-dependent translocation of IGF-1 receptor stimulates membrane expansion and axonal assembly at growth cone via exocytosis of plasmalemmal precursor vesicles in hippocampal neurons (Pfenninger et al., 2003). KIF3 and KIF4 have also been shown to transport membranous organelles through the interaction with fodrin (Takeda et al., 2000) and an unidentified binding protein (Sekine et al., 1994) respectively. KIF3A mediates the transport of PAR-3 to the distal tip of axon in hippocampal neurons, where disruption of PAR-3-KIF3A binding significantly impairs the establishment of neuronal polarity (Nishimura T. et al., 2004). Recently, anterograde axonal transport of lysosome-related organelles is critical for presynaptic biogenesis (Vukoja et al., 2018). Indeed, loss of the kinesin adaptor Arl8 was found to result in an impaired delivery of essential components to the presynaptic site, leading to defects in neurotransmission (Vukoja et al., 2018).

Also, in order to deliver additional plasma membrane to axon tips, axonal transport traffics cytoskeletal components, and mitochondria, providing the structural framework and energy required to support axonal growth (Maday et al., 2014). In Zebrafish, KIF5A transports mitochondria into sensory axons through its C-terminal interaction with the adaptors Trak 1 and Miro1/2 (Campbell et al., 2014). Mutation in KIF5A significantly reduces the proportion and speed of anterogradely moving mitochondria, resulting in a deficit in axonal mitochondria, which promotes axonal degeneration. In addition to fast axonal transport of mitochondria, KIF5A is also involved in slow axonal transports of NFs. Indeed, NF-H, NF-M, and NF-L accumulate in the soma of peripheral sensory neurons in KIF5A inducible knock-out mice. Such somatic accumulation of neurofilament proteins results in axonal reductions, loss of large-caliber axons, and degeneration (Xia et al., 2003; Xiao et al., 2016). Interestingly, KIF5A participates in both fast (mitochondria) and slow (NFs) anterograde axonal transport, simultaneously contributing to the delivery of energy and the structural scaffolds necessary for the elongation and maintenance of axon growth.

Another kinesin, KIF4A, carries integrin $\beta 1$ into immature axons. Indeed, It was shown that depletion of KIF4A by shRNA negatively impacts the level of integrin $\beta 1$ in developing axons and reduces axon elongation in embryonic neurons (Heintz et al., 2014), highlighting the essential role of integrin transport in axonal elongation and initial wiring between immature neurons. It has been previously reported that KIF4A also acts as a regulator of neuronal survival through its interaction and suppression of PARP1 activity in the nucleus; indeed, membrane depolarization induces CaMKII-Ca ${ }^{2+}$ phosphorylation of PARP1, determining its activation after dissociation from KIF4A (Midorikawa et al., 2006). Activation of PARP1 protects mature neurons from apoptosis and allows KIF4A to translocate into the cytoplasm to participate in active transport (Midorikawa et al., 2006). Taken together these observations support a dual function of KIF4A during neuronal development, with KIF4A promoting axonal elongation and connectivity in immature neurons, while protecting mature neurons from apoptosis, thus stabilizing a functional neuronal network. KIF4 was shown to transport anterogradely the P0 protein component of ribosomes along axons (Bisbal et al., 2009). Knockdown of KIF4 in dorsal root ganglion neurons leads to the accumulation of ribosomes in the soma and their disappearance from axons (Bisbal et al., 2009), negatively impacting axonal local protein translation.

Various cellular processes promote growth cone retraction and axonal degeneration of collaterals and branches that failed to establish functional contacts. Kinesin-13 family members, including KIF2A and KIF2C, are important for the homeostatic regulation of neuronal connectivity and brain wiring. KIF2A particularly, while in absence of detectable motor activity, acts as MTs depolymerizer in growth cones to suppress axon collaterals (Homma et al., 2003). Indeed, it has been shown that conditional knock-out of KIF2A promotes mossy fiber sprouting and dendro-axonal conversion of dentate gyrus (DG) cells with aberrant over-extended dendrites gradually acquiring axonal properties in the DG (Homma et al., 2018). Thus, while lacking anterograde motor activity, KIF2A appears to be an essential regulator of neuronal connectivity and the establishment of precise postnatal hippocampal wiring, by determining the pruning of growth cones failing to connect to their postsynaptic target (Figure 1B).

\section{Axonal Trafficking During Synaptogenesis and Synaptic Transmission}

In addition to the establishment and stabilization of neuronal connections, the formation and maintenance of functional synapses are also largely dependent on axonal transport mechanisms. Indeed, synaptic vesicle precursors (SVPs) are known to be transported anterogradely by members of kinesin-3 
family, such as KIF1A and KIF1B (Okada et al., 1995). In KIF1A knock-out mice, neurons accumulate SVPs in the soma and fail to establish normal synaptic connections (Yonekawa et al., 1998), while overexpressing KIF1A promotes the formation of presynaptic terminals (Kondo et al., 2012). SVPs are transported by KIF1A and KIF1B via either liprin- $\alpha$ or DENN/MADD scaffolding complexes (Miller et al., 2005; Niwa et al., 2008). After the delivery to a presynaptic bouton, SVPs can be recycled directly in the terminal (Miller et al., 2005). KIF1A is also believed to contribute to the active transport of synaptic vesicles between neighboring presynaptic release sites, a pool of vesicles referred to as synaptic vesicle "super pool" (Staras et al., 2010). In cultured giant presynaptic terminals, an axosomatic relay synapse in the auditory brainstem considered one of the largest mammalian excitatory synapses, where MTs depolymerization significantly disrupts the fast-directional transport of the vesicles between neighboring release sites, KIF1A has been found to colocalize with two synaptic vesicles markers, synaptophysin and VGLUT1 (Guillaud et al., 2017). These observations suggest that, in mature synapses, KIF1A-mediated transport plays a significant role in the trafficking and delivery of SVPs and fully functional synaptic vesicles during synaptic transmission (Figure 1B). Indeed, KIF1A homolog Unc-104 is involved in synapse maturation and synaptic transmission (Zhang et al., 2017). KIF1A and KIF1B also contribute to the anterograde transport of dense-core vesicles (DCVs), through interaction with liprin- $\alpha$ (Lo et al., 2011), in a way that is regulated by $\mathrm{Ca}^{2+}$ (Stucchi et al., 2018) or through JNK-dependent phosphorylation of synaptotagmin-4 (Bharat et al., 2017). Interestingly, KIF1A associates with DCVs containing Chromogranin-A or BDNF, which move both anterogradely and retrogradely in axons, suggesting that KIF1A might remain attached to DCVs undergoing retrograde transport after the release of BDNF (Stucchi et al., 2018). The anterograde transport from the soma to the synapse of BDNF-containing DCVs is also mediated by KIF5 and its interaction with phosphorylated huntingtin, while their retrograde transport depends on non-phosphorylated huntingtin (Colin et al., 2008). The redundancy of DCVs-transport mechanisms highlights the importance of DCVs targeting and accumulation in the presynaptic compartment and their putative roles in synapse maturation and homeostatic plasticity (Sorra et al., 2006; Tao et al., 2018).

Receptors and voltage-gated channels also need to be efficiently delivered to the synapse to guarantee synaptic transmission. Indeed, conditional KIF5A knock-out mice show behavioral deficits reminiscent of epilepsy, which correlate with a significant reduction in the surface expression of GABA receptors (Nakajima et al., 2012). KIF5A is reported to interact specifically with GABAR-associated protein known to be involved in GABA receptors trafficking, suggesting an important role for KIF5A-mediated transport in inhibitory synaptic transmission. Additionally, KIF5B stalk domain has been shown to directly interact with voltage-gated sodium channel Na1.8 and its overexpression promotes Na1.8 accumulation and neuronal excitability in axons of DRG neurons (Su et al., 2013), suggesting that KIF5B is required for the anterograde transport and function of voltage-gated sodium channels in physiological condition. The correlation between increase in the transport of Na1.8 and KIF5B in pathological conditions, however, needs further investigation (Bao, 2015), and the transport mechanisms of Na1.8 and other sodium channels remain to be fully elucidated. KIF5Bsyntabulin-mediated anterograde transport of mitochondria was also shown to be essential for synaptic maturation, basal and sustained neurotransmitter release, and short-term presynaptic plasticity in superior cervical ganglia (SCG) neurons (Ma et al., 2009). Syntabulin is a syntaxin-binding protein that links vesicles to kinesin heavy chain and thus transports syntaxin-containing vesicles into neuronal processes, and its impairment causes a reduction of mitochondria along the axon, correlating with an acceleration of synaptic depression and the slowdown of the recovery rate after synaptic vesicle depletion (Ma et al., 2009).

\section{Neurodegenerative Diseases Linked to Kinesin Mutations}

In support of their fundamental role in driving axonal transport, mutations of kinesin motors are associated with a spectrum of neurodegenerative diseases (Beijer et al., 2019; Figure 2). De novo mutations of KIF1A have been found in conjunction with cerebellar atrophy, spastic paraparesis, optic nerve atrophy, peripheral neuropathy, epilepsy and cognitive impairment (Citterio et al., 2015; Esmaeeli Nieh et al., 2015; Lee et al., 2015; Ylikallio et al., 2015; Cheon et al., 2017). Some of these mutations are critical for the structure and function of the motor domain and affect axonal transport (Klebe et al., 2012; Lee et al., 2015; Langlois et al., 2016; Samanta and Gokden, 2019). KIF1A was also found mutated in the hereditary sensory and autonomic neuropathy type II (HSANII), an autosomal-recessive disorder characterized by peripheral nerve degeneration (Rivière et al., 2011). More recently, a missense mutation in KIF1A has been shown to increase excitatory synaptic functions in hippocampal neurons and epileptic seizure-like activity in Zebrafish, indicating a direct link between disruption of KIF1A-mediated axonal transport and epileptogenesis (Guo et al., 2020).

KIF5A variants have also been implicated in neurodegenerative diseases such as CMT2, HSP, and ALS (Brenner et al., 2018; Citrigno et al., 2018; Filosto et al., 2018; Nam et al., 2018). Interestingly, the site of the mutation correlates with the clinical phenotype. Indeed, mutations in the motor or neck domain are associated with CMT2 and HSP, while a mutation of KIF5A C-terminus and a mutation that affect splicing are linked to an intermediate slowly progressive form of ALS (Brenner et al., 2018; Citrigno et al., 2018; Filosto et al., 2018; Nam et al., 2018). Several mutations of KIF5A neck and motor domain leading to HSP have been characterized in detail in vitro and have been found to exhibit reduced ATPase activity, microtubule affinity and gliding velocity, which affect the processivity and directionality of the motor and can result in reduced cargo flux and consequent deficient synaptic supply (Ebbing et al., 2008; Goizet et al., 2009; Jennings et al., 2017; Dutta et al., 2018).

An autosomal dominant mutation of KIF1B $\beta$, Q98L, which decreases ATPase activity and motor motility, was initially reported to cause CMT2A in a limited number of pedigrees (Zhao et al., 2001). The lack of confirmation in additional 
families, however, cast some doubts on the relevance of the mutation (Drew et al., 2015). Recently, a novel KIF1B $\beta$ mutation, Y1087C, was identified in connection with CMT2 (Xu et al., 2018). This mutation was shown to impair the binding between KIF1B $\beta$ and the insulin-like growth factor 1 receptor (IGF1R), affecting IGF1R axonal transport, decreasing its exposure on the neuronal surface and consequently negatively impacting Insulin growth factor 1 (IGF-1) signaling, which is essential for neuronal development and survival (Xu et al., 2018). However, whether this mutation is causative of CMT2 or a polymorphism altering IGF1R trafficking is still an object of debate, since the frequency of the Y1087C mutation is much higher than the total amount of CMT2 cases.

\section{REFUELING AXONS AND SYNAPSES, TRAFFICKING OF MITOCHONDRIA AND MRNA GRANULES}

\section{Mitochondrial Trafficking}

The homeostatic regulation of axonal growth, neuronal wiring, and synaptic transmission require an extensive amount of energy and rapid protein turnover in the axons, growth cones, and presynaptic terminals, which need to be supported by local production of ATP and proteins along the axon and at the synapse. Axonal transport plays a key role in these phenomena. In addition to the aforementioned syntabulin and Trak1/Miro, RanBP2 (Cho et al., 2007) and FEZ1 (Ikuta et al., 2007) have also been reported to recruit KIF5B and KIF5C to mitochondria and regulate their mobility and trafficking in axons. Interestingly, abnormal co-aggregates of FEZ1 and Kinesin-1 were described in the brains of mouse models of Alzheimer's disease, suggesting a perturbation of FEZ1-mediated synaptic protein delivery (Butkevich et al., 2016). The existence of several mitochondria adaptor complexes reflects the importance of the axonal transport of mitochondria for the local production of ATP needed to sustain axonal functions (Saxton and Hollenbeck, 2012). Therefore, it is not surprising that, even in the absence of KIF5 mediated transport, a limited fraction of mitochondria is still transported by other kinesins. Indeed, KIF1B $\alpha$ and KIF1C have been reported to contribute to mitochondria transport through interaction with KBP (Nangaku et al., 1994; Wozniak et al., 2005), as well as KLP6, an uncharacterized kinesin homolog that regulates both mitochondrial morphology and transport (Tanaka et al., 2011).

Transported axonal mitochondria need to remain functional to provide adequate energy support over long distances. Thus, mutations affecting the integrity of mitochondrial morphology and the dynamic balance between their fission and fusion, influence axonal transport (Beijer et al., 2019; Figure 2). Indeed, CMT2A, the most prominent subtype of CMT, is characterized by mutations of mitofusin 2 (MFN2), an outer mitochondrial membrane GTPase that plays a critical role in mitochondrial fusion (Verhoeven et al., 2006). MFN2 has been shown to interact with the Miro/Milton adaptor complex essential for mitochondrial mobilization along MTs. The mutant form disrupts the function of the adaptor complex, thus inducing mitochondrial clustering/aggregation along the axonal length (Baloh et al., 2007; Misko et al., 2010). Interestingly, both mutations in the Miro/Milton complex mediating its interaction with MT and as well as NF-L mutants, indirectly affect mitochondrial transport and localization (Ni et al., 2015). In addition to fusion, dysregulation of mitochondrial fission is also causative of CMT. Recessive mutations of the ganglioside-induced differentiation-associated protein 1 (GDAP1), a mitochondrial factor whose activity is dependent on the fission factors Fis1 and the dynamin-related protein 1 (Drp1), determines a reduction in mitochondrial fission activity, while the dominant ones negatively impact mitochondrial fusion (Niemann et al., 2009).

Mitochondrial transport and function are also affected by alteration of the endoplasmic reticulum (ER) and its contacts with mitochondria, where $\mathrm{Ca}^{2+}$ exchange between the two organelles occurs. Indeed, disruption of the ER network has been shown to result in axonal degeneration (Yalçın et al., 2017). Mitochondrial $\mathrm{Ca}^{2+}$ uptake is required for correct intracellular signaling, homeostasis, and mitochondrial integrity and transport, therefore mutations in $\mathrm{Ca}^{2+}$ channels also lead to mitochondrial dysfunction (Kumar et al., 2018). The integral ER membrane protein vesicle-associated membrane protein-associated protein B (VAPB), which is associated to ALS (Nishimura A. L. et al., 2004; Chen et al., 2010), interacts with the outer mitochondrial membrane and its mutation impacts mitochondrial $\mathrm{Ca}^{2+}$ uptake and induces the formation of abnormal ER inclusions (De Vos et al., 2012). Interestingly, the ER fusion protein atlastin 3 (ATL3) has been identified in patients with hereditary sensory and autonomic neuropathy (Guelly et al., 2011; Fischer et al., 2014; Kornak et al., 2014). Defects in ATL3 result in an increased number of ER-mitochondria contact sites augmented $\mathrm{Ca}^{2+}$ crosstalk between the two organelles and decreased number and motility of axonal mitochondria (Krols et al., 2019).

Mutations in tRNA synthetases, enzymes that attach amino acids to their cognate tRNA molecules in the cytoplasm and mitochondria, affect mitochondrial function and have been associated with a number of human neurodegenerative diseases (Antonellis and Green, 2008; Spaulding et al., 2016). Indeed, Glycyl-tRNA synthetase (GARS) dominant mutations have been described in inherited neuropathies such as CMT2D and dHMN with upper limb predominance (dHMN-V; Xie et al., 2007; Antonellis and Green, 2008). Interestingly, dominant GARS mutations impair neuronal mitochondrial metabolism and cause alterations of VAPB and mitochondrial calcium uptake (Boczonadi et al., 2018). While the disease does not seem to be caused by a loss of the canonical function of these enzymes (Storkebaum et al., 2009; Stum et al., 2011; Ermanoska et al., 2014), mutations of mostly the cytosolic form of tRNA synthetase have been shown to result in toxic gain of function, which impair the signaling output of different families of neurotrophic factor receptors (Stum et al., 2011; He et al., 2015; Sleigh et al., 2017a,b).

\section{mRNA Axonal Trafficking}

We have previously discussed how the correct arrangement of the cytoskeleton and the coordinated action of a cohort 


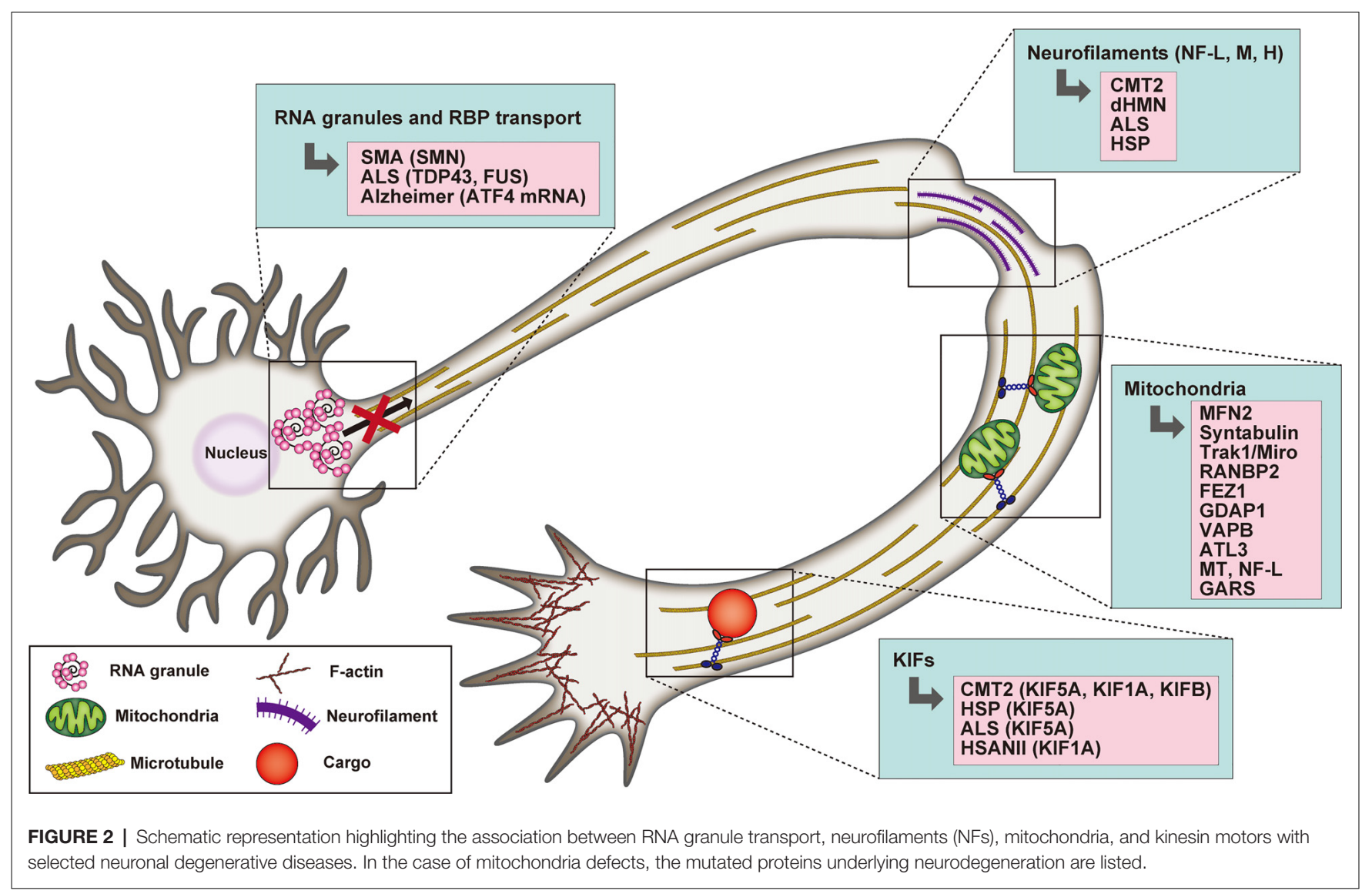

of molecular motors are essential for the establishment and maintenance of axonal biology. As axons depend on the delivery of proteins and organelles, fast and local availability of proteins to sustain axonal high turnover rate can also be supported by local translation. While mRNA transport and local protein translation in dendrites have been well documented, the mechanisms of axonal mRNA targeting and translation are still the subject of intense investigation. Indeed, several pieces of evidence have shown that axonally synthesized proteins support axon function, survival, and growth (Sahoo et al., 2018b).

Early observations highlighting how, after detachment from the cell bodies, growth cones were still able to respond to guidance cues in a manner that was dependent on calcium signaling and local protein synthesis, supported the existence of axonal translation (Campbell and Holt, 2001; Ming et al., 2002). The identity and concentration as well as the localization of the cue determine the extent and the nature of the translational response (Brittis et al., 2002; Leung et al., 2006; Manns et al., 2012; Nédelec et al., 2012). Chemotrophic signals, for instance, are known to elicit mRNA transport into axons and growth cones. Indeed, Neurotrophin-3 (NT3) induces targeting and translation of $\beta$-actin mRNA into growth cones, which correlates with an increase in growth cone protrusions (Zhang et al., 2001). NGF triggers $\beta$-actin mRNA transport into axons (Willis et al., 2005). $\beta$-actin is also involved in calcium-mediated growth cone guidance, which is affected by inhibition of $\beta$-actin local synthesis or misslocalization of its mRNA (Yao et al., 2006; Welshhans and Bassell, 2011).

RNA-binding proteins (RBP) recognize specific sequence located mostly in the $5^{\prime}$ and $3^{\prime}$ UTR regions of mRNA (emerging evidences implicate the coding region as well), and bind to kinesins or dynein to be transported to axons or dendrites; while the $5^{\prime}$ UTR elements are often linked to translation regulation, $3^{\prime}$ UTRs regions are essential for targeting to specific subcellular compartments (Hüttelmaier et al., 2005; Chatterjee and Pal, 2009; Merianda et al., 2013; Tushev et al., 2018). The aforementioned $\beta$-actin mRNA, for instance, is localized to growth cones by the RBP Zipcode-Binding Protein 1 (ZBP1; Yao et al., 2006). mRNA, RBP and ribosomes are co-transported in large RNA granules, which have been linked to stress granules, where mRNA translation is actively repressed (Kanai et al., 2004; Sahoo et al., 2018a; Pushpalatha and Besse, 2019). These granules display anterograde and retrograde microtubule-based motor movements (Gumy et al., 2014). In addition to KIF5, KIF1Bb might also be involved in mRNA transport, although the mechanism of interaction remains unclear (Lyons et al., 2009).

Axonal injuries are known to trigger local mRNA translation of proteins that will initiate a regenerative transcriptional program in the nucleus through a retrograde signaling cascade originating from the site of injury (Hanz et al., 2003; Perlson et al., 2005; Yudin et al., 2008; Rishal and Fainzilber, 2014; Terenzio et al., 2018). Perturbation of this retrograde mechanisms can 
cause a delay in axonal regeneration and decrease neuronal survival (Perry et al., 2012; Sahoo et al., 2018b; Terenzio et al., 2018). Nerve injury also induces local translation of mTOR, which in turn controls the axonal synthesis of several retrograde injury signals; thus, disruption of mTOR activity decreases neuronal survival after injury (Terenzio et al., 2018).

Axonal protein synthesis plays also important roles in neurological diseases such as SMA (Spinal Muscular Atrophy), ALS, or Alzheimer's disease. Indeed, a growing list of mRNAs and RNA binding proteins has been described to be axonally mislocalized in neurodegenerative disease (reviewed in Khalil et al., 2018; Figure 2). For example, loss of SMN significantly alters axonal mRNA levels required for axonal growth and synaptic transmission (Saal et al., 2014; Khalil et al., 2018). Indeed, alterations in the local synthesis of key axonal survival proteins implicated in neurodegenerative diseases have been observed (Kar et al., 2018; Khalil et al., 2018). For instance, expression of the ALS mutants of RNA-binding protein TDP-43 showed decreased mobility of axonal RNPs and reduced axonal transport in motor neurons (Alami et al., 2014), and ALS-causing TDP-43 mutations alter the axonal content of both mRNAs and miRNAs in cultured spinal motor neurons (Rotem et al., 2017). Treatment of hippocampal neurons with amyloid peptide A $\beta 1-42$ promotes axonal translation of Atf 4 mRNA and ATF4 retrograde transport leading to neuronal cell death (Baleriola et al., 2014). A recent study showed mRNA translation in axons in connection with late endosomes (Cioni et al., 2019). Interestingly, Rab7a mutants, including those associated with CMT2B, negatively impacted axonal protein synthesis, impaired mitochondrial function, and axonal viability (Cioni et al., 2019). This study highlights the high degree of crossinteraction between different axonal organelles and how these vesicles act as platforms for several signaling pathways as well as different biological cellular functions that have not been associated with intracellular trafficking until recently.

\section{CONCLUSIONS AND PERSPECTIVES}

The combined use of transgenic animal models, primary neuronal cultures, neurons derived from human inducible pluripotent stem cells, in addition to the recent technological advances in proteomics, drug design, and super-resolution microscopy has allowed the in-depth study of the underlying molecular mechanisms behind neurodegenerative diseases (Millecamps et al., 2006; De Vos and Hafezparast, 2017). Many key questions, however, remain open, including the precise molecular identity of the transported vesicles, whether or not it is subjected to change along axons and whether there are any region-specific differences in organelle trafficking within the axonal compartment. Rapid advances in high resolution live imaging in vitro and in vivo will provide a technological platform to further our knowledge of these phenomena. For example, the trafficking of membrane-less organelles such as stress and/or RNA granules is critical for the maintenance of neuronal homeostasis. The presence of mRNAs granules implies that selected proteins can be locally translated in axons and synapses. Identifying which mRNA can be transported, by which trafficking pathways, and where translation takes place, is, thus, paramount to our understanding of axonal biology. Luckily, several novel proteomic approaches have been designed to identify newly synthesized proteins (Forester et al., 2018; Koppel and Fainzilber, 2018; Terenzio et al., 2018; Holt et al., 2019), together with new imaging tools engineered to visualize localized mRNA and protein translation (Morisaki et al., 2016; Wu et al., 2016). These new technological developments will give us valuable insights into the cooperation between intracellular transport mechanisms and local protein synthesis in both physiological and pathological conditions.

LPS of biomolecules has also recently emerged as a novel fundamental mechanism underlying subcellular organization and regulation (Chen et al., 2020). The formation of highly condensed molecular assemblies, also known as membrane-less organelles or bio-condensates, within aqueous solutions such as the cytoplasm, plays critical roles in the maintenance of neuronal functions and in neurodegeneration (ElbaumGarfinkle, 2019). The formation of various components of mRNA and/or stress granules that are targeted to and transported in axons have also been shown to be regulated by LPS. Indeed, the Fragile X Mental Retardation Protein (FMRP) undergoes phosphorylation-dependent phase separation with RNA in a synaptic activity-dependent manner to generate membrane-lessRNA-protein transport granules (Tsang et al., 2019). TDP43 low-complexity domain phase-separates to form cytoplasmic stress granules (Babinchak et al., 2019) and the persistence of phase-separated TDP43 independently of stress granules can induce neuronal cell death (Gasset-Rosa et al., 2019). TDP-43-containing axonal mRNA transport granules have also been reported to display liquid-like properties (Gopal et al., 2017). Additionally, synapsin-1 has been demonstrated to phaseseparate and promote synaptic vesicles clustering at the synapse regulating the mobility of synaptic vesicles in axon terminals (Milovanovic et al., 2018). Active zone protein RIM-1 has also been shown to undergo a phase transition, which might represent the basic mechanism underlying the organization of release sites at the synapses (Wu et al., 2019). Lastly, LPS of disordered proteins such as Tau in Alzheimer's disease (Ambadipudi et al., 2017; Wegmann et al., 2018), FUS/TDP43 in ALS (Murakami et al., 2015; Patel et al., 2015; Conicella et al., 2016), huntingtin protein in Huntington's disease (Peskett et al., 2018) have been recently reported to be critical for their pathological aggregation and toxicity. Similar mechanisms might also be involved in the aggregation of $\beta$-amyloid precursor proteins in Parkinson's disease (Boke et al., 2016; de Gap et al., 2019) and $\alpha$-synuclein.

Although the contribution of LPS to long-range transport in neurons remains an open question, perturbations in LPS likely affect the formation of phase-separated transport granules (reviewed in Nötzel et al., 2018). A recent study has reported that the long-distance trafficking of mRNA granule/lysosome complex depends on LPS of annexin 11 and that this mechanism is critical for their axonal transport (Liao et al., 2019). Another in vitro study also suggested that prolonged LPS of Tau can lead to the formation and aggregation of pathogenic Tau, a form of Tau known to affect axonal transport (Kanaan et al., 2020). Though we have just started to decipher the molecular 
mechanisms leading to the formation of these bio-condensates, their recruitment onto molecular motors and their targeting to axons and synapses, the discussed pathological aggregation of various neuronal proteins, point to a plausible correlation between perturbations in protein LPS and neurodegeneration. Thus, the integrative study of transport mechanisms, local protein synthesis, and LPSs is critical to reconstructing a comprehensive picture of the multiple cellular and molecular pathways that cooperatively or sequentially take place to efficiently regulate axonal functions.

\section{REFERENCES}

Ackerley, S., Grierson, A. J., Banner, S., Perkinton, M. S., Brownlees, J., Byers, H. L., et al. (2004). p38 $\alpha$ stress-activated protein kinase phosphorylates neurofilaments and is associated with neurofilament pathology in amyotrophic lateral sclerosis. Mol. Cell. Neurosci. 26, 354-364. doi: 10.1016/j.mcn.2004. 02.009

Ackerley, S., Grierson, A. J., Brownlees, J., Thornhill, P., Anderton, B. H., Leigh, P. N., et al. (2000). Glutamate slows axonal transport of neurofilaments in transfected neurons. J. Cell Biol. 150, 165-175. doi: 10.1083/jcb. 150.1.165

Ackerley, S., James, P. A., Kalli, A., French, S., Davies, K. E., and Talbot, K. (2006). A mutation in the small heat-shock protein HSPB1 leading to distal hereditary motor neuronopathy disrupts neurofilament assembly and the axonal transport of specific cellular cargoes. Hum. Mol. Genet. 15, 347-354. doi: $10.1093 / \mathrm{hmg} / \mathrm{ddi} 452$

Ackerley, S., Thornhill, P., Grierson, A. J., Brownlees, J., Anderton, B. H., Leigh, P. N., et al. (2003). Neurofilament heavy chain side arm phosphorylation regulates axonal transport of neurofilaments. J. Cell Biol. 161, 489-495. doi: $10.1083 /$ jcb. 200303138

Alami, N. H., Smith, R. B., Carrasco, M. A., Williams, L. A., Winborn, C. S., Han, S. S. W., et al. (2014). Axonal transport of TDP-43 mRNA granules is impaired by ALS-causing mutations. Neuron 81, 536-543. doi: 10.1016/j. neuron.2013.12.018

Al-Chalabi, A., Andersen, P. M., Nilsson, P., Chioza, B., Andersson, J. L., Russ, C., et al. (1999). Deletions of the heavy neurofilament subunit tail in amyotrophic lateral sclerosis. Hum. Mol. Genet. 8, 157-164. doi: 10.1093/hmg/ 8.2.157

Ambadipudi, S., Biernat, J., Riedel, D., Mandelkow, E., and Zweckstetter, M. (2017). Liquid-liquid phase separation of the microtubule-binding repeats of the Alzheimer-related protein Tau. Nat. Commun. 8:275. doi: 10.1038/s41467017-00480-0

Antonellis, A., and Green, E. D. (2008). The role of aminoacyl-tRNA synthetases in genetic diseases. Annu. Rev. Genomics Hum. Genet. 9, 87-107. doi: 10.1146/annurev.genom.9.081307.164204

Atherton, J., Farabella, I., Yu, I.-M., Rosenfeld, S. S., Houdusse, A., Topf, M., et al. (2014). Conserved mechanisms of microtubule-stimulated ADP release, ATP binding, and force generation in transport kinesins. eLife 3:e03680. doi: 10.7554/eLife.03680

Babinchak, W. M., Haider, R., Dumm, B. K., Sarkar, P., Surewicz, K., Choi, J.K., et al. (2019). The role of liquid-liquid phase separation in aggregation of the TDP-43 low-complexity domain. J. Biol. Chem. 294, 6306-6317. doi: $10.1074 /$ jbc.RA118.007222

Bajaj, N. P., and Miller, C. C. (1997). Phosphorylation of neurofilament heavychain side-arm fragments by cyclin-dependent kinase- 5 and glycogen synthase kinase- $3 \alpha$ in transfected cells. J. Neurochem. 69, 737-743. doi: 10.1046/j.14714159.1997.69020737.x

Baleriola, J., Walker, C. A., Jean, Y. Y., Crary, J. F., Troy, C. M., Nagy, P. L., et al. (2014). Axonally synthesized ATF4 transmits a neurodegenerative signal across brain regions. Cell 158, 1159-1172. doi: 10.1016/j.cell.2014.07.001

Baloh, R. H., Schmidt, R. E., Pestronk, A., and Milbrandt, J. (2007). Altered axonal mitochondrial transport in the pathogenesis of Charcot-MarieTooth disease from mitofusin 2 mutations. J. Neurosci. 27, 422-430. doi: 10.1523/JNEUROSCI.4798-06.2007

\section{AUTHOR CONTRIBUTIONS}

LG, SE-A and MT participated in the design and writing of this review. MO made the figures.

\section{FUNDING}

This work was generously funded by Japan Society for the Promotion of Science (JSPS)/Kakenhi \#18K16467 to LG and JSPS/Kakenhi \#20K07458 to MT.

Bao, L. (2015). Trafficking regulates the subcellular distribution of voltagegated sodium channels in primary sensory neurons. Mol. Pain 11:61. doi: 10.1186/s12990-015-0065-7

Beijer, D., Sisto, A., Van Lent, J., Baets, J., and Timmerman, V. (2019). Defects in axonal transport in inherited neuropathies. J. Neuromuscul. Dis. 6, 401-419. doi: 10.3233/jnd-190427

Bentley, M., and Banker, G. (2016). The cellular mechanisms that maintain neuronal polarity. Nat. Rev. Neurosci. 17, 611-622. doi: 10.1038/nrn. 2016.100

Bharat, V., Siebrecht, M., Burk, K., Ahmed, S., Reissner, C., Kohansal-Nodehi, M., et al. (2017). Capture of dense core vesicles at synapses by JNK-dependent phosphorylation of synaptotagmin-4. Cell Rep. 21, 2118-2133. doi: 10.1016/j. celrep.2017.10.084

Bisbal, M., Wojnacki, J., Peretti, D., Ropolo, A., Sesma, J., Jausoro, I., et al. (2009). KIF4 mediates anterograde translocation and positioning of ribosomal constituents to axons. J. Biol. Chem. 284, 9489-9497. doi: 10.1074/jbc. m808586200

Boczonadi, V., Meyer, K., Gonczarowska-Jorge, H., Griffin, H., Roos, A., Bartsakoulia, M., et al. (2018). Mutations in glycyl-tRNA synthetase impair mitochondrial metabolism in neurons. Hum. Mol. Genet. 27, 2187-2204. doi: $10.1093 / \mathrm{hmg} / \mathrm{ddy} 127$

Boke, E., Ruer, M., Wühr, M., Coughlin, M., Lemaitre, R., Gygi, S. P., et al. (2016). Amyloid-like self-assembly of a cellular compartment. Cell 166, 637-650. doi: 10.1016/j.cell.2016.06.051

Bouhy, D., Juneja, M., Katona, I., Holmgren, A., Asselbergh, B., De Winter, V., et al. (2018). A knock-in/knock-out mouse model of HSPB8-associated distal hereditary motor neuropathy and myopathy reveals toxic gain-of-function of mutant Hspb8. Acta Neuropathol. 135, 131-148. doi: 10.1007/s00401-0171756-0

Brady, S. T., and Morfini, G. A. (2017). Regulation of motor proteins, axonal transport deficits and adult-onset neurodegenerative diseases. Neurobiol. Dis. 105, 273-282. doi: 10.1016/j.nbd.2017.04.010

Brenner, D., Yilmaz, R., Müller, K., Grehl, T., Petri, S., Meyer, T., et al. (2018). Hot-spot KIF5A mutations cause familial ALS. Brain 141, 688-697. doi: 10.1093/brain/awx370

Brittis, P. A., Lu, Q., and Flanagan, J. G. (2002). Axonal protein synthesis provides a mechanism for localized regulation at an intermediate target. Cell 110, 223-235. doi: 10.1016/s0092-8674(02)00813-9

Brownlees, J., Ackerley, S., Grierson, A. J., Jacobsen, N. J. O., Shea, K., Anderton, B. H., et al. (2002). Charcot-Marie-Tooth disease neurofilament mutations disrupt neurofilament assembly and axonal transport. Hum. Mol. Genet. 11, 2837-2844. doi: 10.1093/hmg/ 11.23.2837

Butkevich, E., Härtig, W., Nikolov, M., Erck, C., Grosche, J., Urlaub, H., et al. (2016). Phosphorylation of FEZ1 by Microtubule Affinity Regulating Kinases regulates its function in presynaptic protein trafficking. Sci. Rep. 6:26965. doi: 10.1038/srep26965

Campbell, D. S., and Holt, C. E. (2001). Chemotropic responses of retinal growth cones mediated by rapid local protein synthesis and degradation. Neuron 32, 1013-1026. doi: 10.1016/s0896-6273(01)00551-7

Campbell, P. D., Shen, K., Sapio, M. R., Glenn, T. D., Talbot, W. S., and Marlow, F. L. (2014). Unique function of Kinesin Kif5A in localization of mitochondria in axons. J. Neurosci. 34, 14717-14732. doi: 10.1523/JNEUROSCI.2770-14.2014 
Cao, T., Chang, W., Masters, S., and Mooseker, M. (2004). Myosin-Va binds to and mechanochemically couples microtubules to actin filaments. Mol. Biol. Cell 15, 151-161. doi: 10.1091/mbc.e03-07-0504

Chatterjee, S., and Pal, J. K. (2009). Role of $5^{\prime}$ - and $3^{\prime}$-untranslated regions of mRNAs in human diseases. Biol. Cell 101, 251-262. doi: 10.1042/BC20080104

Chen, H.-J., Anagnostou, G., Chai, A., Withers, J., Morris, A., Adhikaree, J., et al. (2010). Characterization of the properties of a novel mutation in VAPB in familial amyotrophic lateral sclerosis. J. Biol. Chem. 285, 40266-40281. doi: 10.1074/jbc.M110.161398

Chen, X., Wu, X., Wu, H., and Zhang, M. (2020). Phase separation at the synapse. Nat. Neurosci. 23, 301-310. doi: 10.1038/s41593-019-0579-9

Cheon, C. K., Lim, S.-H., Kim, Y.-M., Kim, D., Lee, N.-Y., Yoon, T.-S., et al. (2017). Autosomal dominant transmission of complicated hereditary spastic paraplegia due to a dominant negative mutation of KIF1A, SPG30 gene. Sci. Rep. 7:12527. doi: 10.1038/s41598-017-12999-9

Cho, K., Cai, Y., Yi, H., Yeh, A., Aslanukov, A., and Ferreira, P. A. (2007). Association of the kinesin-binding domain of RanBP2 to KIF5B and KIF5C determines mitochondria localization and function. Traffic 8, 1722-1735. doi: 10.1111/j.1600-0854.2007.00647.x

Cioni, J.-M., Lin, J. Q., Holtermann, A. V., Koppers, M., Jakobs, M. A. H., Azizi, A., et al. (2019). Late endosomes act as mRNA translation platforms and sustain mitochondria in axons. Cell 176, 56.e15-72.e15. doi: 10.1016/j.cell.2018.11.030

Citrigno, L., Magariello, A., Pugliese, P., Di Palma, G., Conforti, F. L., Petrone, A., et al. (2018). Kinesins in neurological inherited diseases: a novel motor-domain mutation in KIF5A gene in a patient from Southern Italy affected by hereditary spastic paraplegia. Acta Neurol. Belg. 118, 643-646. doi: 10.1007/s13760-0181039-0

Citterio, A., Arnoldi, A., Panzeri, E., Merlini, L., D’Angelo, M. G., Musumeci, O., et al. (2015). Variants in KIF1A gene in dominant and sporadic forms of hereditary spastic paraparesis. J. Neurol. 262, 2684-2690. doi: 10.1007/s00415015-7899-9

Colin, E., Zala, D., Liot, G., Rangone, H., Borrell-Pagès, M., Li, X.-J., et al. (2008). Huntingtin phosphorylation acts as a molecular switch for anterograde/retrograde transport in neurons. EMBO J. 27, 2124-2134. doi: 10.1038/emboj.2008.133

Collard, J. F., Côté, F., and Julien, J. P. (1995). Defective axonal transport in a transgenic mouse model of amyotrophic lateral sclerosis. Nature 375, 61-64. doi: 10.1038/375061a0

Conicella, A. E., Zerze, G. H., Mittal, J., and Fawzi, N. L. (2016). ALS mutations disrupt phase separation mediated by $\alpha$-helical structure in the TDP-43 low-complexity C-terminal domain. Structure 24, 1537-1549. doi: 10.1016/j. str.2016.07.007

de Gap, O. A., Y, C., Jl, S., and Tcrg, V. (2019). Liquid-liquid phase transitions and amyloid aggregation in proteins related to cancer and neurodegenerative diseases. Adv. Protein Chem. Struct. Biol. 118, 289-331. doi: 10.1016/bs.apcsb. 2019.08.002

De Vos, K. J., and Hafezparast, M. (2017). Neurobiology of axonal transport defects in motor neuron diseases: opportunities for translational research? Neurobiol. Dis. 105, 283-299. doi: 10.1016/j.nbd.2017.02.004

De Vos, K. J., Mórotz, G. M., Stoica, R., Tudor, E. L., Lau, K.-F., Ackerley, S., et al. (2012). VAPB interacts with the mitochondrial protein PTPIP51 to regulate calcium homeostasis. Hum. Mol. Genet. 21, 1299-1311. doi: $10.1093 / \mathrm{hmg} / \mathrm{ddr} 559$

Desai, A., and Mitchison, T. J. (1997). Microtubule polymerization dynamics. Annu. Rev. Cell Dev. Biol. 13, 83-117. doi: 10.1146/annurev.cellbio.13.1.83

Dion, P. A., Daoud, H., and Rouleau, G. A. (2009). Genetics of motor neuron disorders: new insights into pathogenic mechanisms. Nat. Rev. Genet. 10, 769-782. doi: 10.1038/nrg2680

Dixit, R., Ross, J. L., Goldman, Y. E., and Holzbaur, E. L. F. (2008). Differential regulation of dynein and kinesin motor proteins by tau. Science 319, 1086-1089. doi: 10.1126/science.1152993

Drew, A. P., Zhu, D., Kidambi, A., Ly, C., Tey, S., Brewer, M. H., et al. (2015). Improved inherited peripheral neuropathy genetic diagnosis by whole-exome sequencing. Mol. Genet. Genomic Med. 3, 143-154. doi: 10.1002/mgg3.126

Dutta, M., Diehl, M. R., Onuchic, J. N., and Jana, B. (2018). Structural consequences of hereditary spastic paraplegia disease-related mutations in kinesin. Proc. Natl. Acad. Sci. U S A 115, E10822-E10829. doi: 10.1073/pnas. 1810622115
d'Ydewalle, C., Krishnan, J., Chiheb, D. M., Damme, P. V., Irobi, J., Kozikowski, A. P., et al. (2011). HDAC6 inhibitors reverse axonal loss in a mouse model of mutant HSPB1-induced Charcot-Marie-Tooth disease. Nat. Med. 17, 968-974. doi: 10.1038/nm.2396

Ebbing, B., Mann, K., Starosta, A., Jaud, J., Schöls, L., Schüle, R., et al. (2008). Effect of spastic paraplegia mutations in KIF5A kinesin on transport activity. Hum. Mol. Genet. 17, 1245-1252. doi: 10.1093/hmg/ddn014

Elbaum-Garfinkle, S. (2019). Matter over mind: liquid phase separation and neurodegeneration. J. Biol. Chem. 294, 7160-7168. doi: 10.1074/jbc.REV118. 001188

Ermanoska, B., Motley, W. W., Leitão-Gonçalves, R., Asselbergh, B., Lee, L. H., De Rijk, P., et al. (2014). CMT-associated mutations in glycyl- and tyrosyl-tRNA synthetases exhibit similar pattern of toxicity and share common genetic modifiers in Drosophila. Neurobiol. Dis. 68, 180-189. doi: 10.1016/j.nbd.2014. 04.020

Esmaeeli Nieh, S., Madou, M. R. Z., Sirajuddin, M., Fregeau, B., McKnight, D., Lexa, K., et al. (2015). De novo mutations in KIF1A cause progressive encephalopathy and brain atrophy. Ann. Clin. Transl. Neurol. 2, 623-635. doi: 10.1002/acn3.198

Farías, G. G., Guardia, C. M., Britt, D. J., Guo, X., and Bonifacino, J. S. (2015). Sorting of dendritic and axonal vesicles at the pre-axonal exclusion zone. Cell Rep. 13, 1221-1232. doi: 10.1016/j.celrep.2015.09.074

Figlewicz, D. A., Krizus, A., Martinoli, M. G., Meininger, V., Dib, M., Rouleau, G. A., et al. (1994). Variants of the heavy neurofilament subunit are associated with the development of amyotrophic lateral sclerosis. Hum. Mol. Genet. 3, 1757-1761. doi: 10.1093/hmg/3.10.1757

Filosto, M., Piccinelli, S. C., Palmieri, I., Necchini, N., Valente, M., Zanella, I., et al. (2018). A novel mutation in the stalk domain of KIF5A causes a slowly progressive atypical motor syndrome. J. Clin. Med. 8:17. doi: $10.3390 / \mathrm{jcm} 8010017$

Fischer, D., Schabhüttl, M., Wieland, T., Windhager, R., Strom, T. M., and Auer-Grumbach, M. (2014). A novel missense mutation confirms ATL3 as a gene for hereditary sensory neuropathy type 1. Brain 137:e286. doi: 10.1093/brain/awu091

Forester, C. M., Zhao, Q., Phillips, N. J., Urisman, A., Chalkley, R. J., OsesPrieto, J. A., et al. (2018). Revealing nascent proteomics in signaling pathways and cell differentiation. Proc. Natl. Acad. Sci. U S A 115, 2353-2358. doi: 10.1073/pnas.1707514115

Forrest, S. L., Kril, J. J., Stevens, C. H., Kwok, J. B., Hallupp, M., Kim, W. S., et al. (2018). Retiring the term FTDP-17 as MAPT mutations are genetic forms of sporadic frontotemporal tauopathies. Brain 141, 521-534. doi: 10.1093/brain/awx328

Fu, M.-M., and Holzbaur, E. L. F. (2014). Integrated regulation of motor-driven organelle transport by scaffolding proteins. Trends Cell Biol. 24, 564-574. doi: 10.1016/j.tcb.2014.05.002

Gasset-Rosa, F., Lu, S., Yu, H., Chen, C., Melamed, Z., Guo, L., et al. (2019). Cytoplasmic TDP-43 De-mixing independent of stress granules drives inhibition of nuclear import, loss of nuclear TDP-43 and cell death. Neuron 102, 339.e7-357.e7. doi: 10.1016/j.neuron.2019.02.038

Gentil, B. J., Mushynski, W. E., and Durham, H. D. (2013). Heterogeneity in the properties of NEFL mutants causing Charcot-Marie-Tooth disease results in differential effects on neurofilament assembly and susceptibility to intervention by the chaperone-inducer, celastrol. Int. J. Biochem. Cell Biol. 45, 1499-1508. doi: 10.1016/j.biocel.2013.04.009

Goizet, C., Boukhris, A., Mundwiller, E., Tallaksen, C., Forlani, S., Toutain, A., et al. (2009). Complicated forms of autosomal dominant hereditary spastic paraplegia are frequent in SPG10. Hum. Mutat. 30, E376-E385. doi: 10.1002/humu.20920

Gopal, P. P., Nirschl, J. J., Klinman, E., and Holzbaur, E. L. F. (2017). Amyotrophic lateral sclerosis-linked mutations increase the viscosity of liquid-like TDP-43 RNP granules in neurons. Proc. Natl. Acad. Sci. U S A 114, E2466-E2475. doi: 10.1073/pnas.1614462114

Grant, P., and Pant, H. C. (2000). Neurofilament protein synthesis and phosphorylation. J. Neurocytol. 29, 843-872. doi: 10.1023/a:1010999509251

Gros-Louis, F., Larivière, R., Gowing, G., Laurent, S., Camu, W., Bouchard, J.P., et al. (2004). A frameshift deletion in peripherin gene associated with amyotrophic lateral sclerosis. J. Biol. Chem. 279, 45951-45956. doi: 10.1074/jbc. M408139200 
Guedes-Dias, P., and Holzbaur, E. L. F. (2019). Axonal transport: driving synaptic function. Science 366:eaaw9997. doi: 10.1126/science.aaw9997

Guedes-Dias, P., Nirschl, J. J., Abreu, N., Tokito, M. K., Janke, C., Magiera, M. M., et al. (2019). Kinesin-3 responds to local microtubule dynamics to target synaptic cargo delivery to the presynapse. Curr. Biol. 29, 268.e8-282.e8. doi: 10.1016/j.cub.2018.11.065

Guelly, C., Zhu, P.-P., Leonardis, L., Papić, L., Zidar, J., Schabhüttl, M., et al. (2011). Targeted high-throughput sequencing identifies mutations in atlastin-1 as a cause of hereditary sensory neuropathy type I. Am. J. Hum. Genet. 88, 99-105. doi: 10.1016/j.ajhg.2010.12.003

Guillaud, L., Dimitrov, D., and Takahashi, T. (2017). Presynaptic morphology and vesicular composition determine vesicle dynamics in mouse central synapses. eLife 6:e24845. doi: 10.7554/eLife.24845

Guillaud, L., Wong, R., and Hirokawa, N. (2008). Disruption of KIF17Mint1 interaction by CaMKII-dependent phosphorylation: a molecular model of kinesin-cargo release. Nat. Cell Biol. 10, 19-29. doi: 10.1038/ncb1665

Gumy, L. F., Katrukha, E. A., Kapitein, L. C., and Hoogenraad, C. C. (2014). New insights into mRNA trafficking in axons. Dev. Neurobiol. 74, 233-244. doi: 10.1002/dneu.22121

Guo, Y., Chen, Y., Yang, M., Xu, X., Lin, Z., Ma, J., et al. (2020). A rare KIF1A missense mutation enhances synaptic function and increases seizure activity. Front. Genet. 11:61. doi: 10.3389/fgene.2020.00061

Hanz, S., Perlson, E., Willis, D., Zheng, J.-Q., Massarwa, R., Huerta, J. J., et al. (2003). Axoplasmic importins enable retrograde injury signaling in lesioned nerve. Neuron 40, 1095-1104. doi: 10.1016/s0896-6273(03)00770-0

He, W., Bai, G., Zhou, H., Wei, N., White, N. M., Lauer, J., et al. (2015). CMT2D neuropathy is linked to the neomorphic binding activity of glycyl-tRNA synthetase. Nature 526, 710-714. doi: 10.1038/nature15510

Heintz, T. G., Heller, J. P., Zhao, R., Caceres, A., Eva, R., and Fawcett, J. W. (2014). Kinesin KIF4A transports integrin $\beta 1$ in developing axons of cortical neurons. Mol. Cell. Neurosci. 63, 60-71. doi: 10.1016/j.mcn.2014.09.003

Hendricks, A. G., Perlson, E., Ross, J. L., Schroeder, H. W., Tokito, M., and Holzbaur, E. L. F. (2010). Motor coordination via a tug-of-war mechanism drives bidirectional vesicle transport. Curr. Biol. 20, 697-702. doi: 10.1016/j. cub.2010.02.058

Hergesheimer, R. C., Chami, A. A., de Assis, D. R., Vourc'h, P., Andres, C. R., Corcia, P., et al. (2019). The debated toxic role of aggregated TDP-43 in amyotrophic lateral sclerosis: a resolution in sight? Brain 142, 1176-1194. doi: 10.1093/brain/awz078

Hirokawa, N., and Tanaka, Y. (2015). Kinesin superfamily proteins (KIFs): various functions and their relevance for important phenomena in life and diseases. Exp. Cell Res. 334, 16-25. doi: 10.1016/j.yexcr.2015.02.016

Hirokawa, N., Niwa, S., and Tanaka, Y. (2010). Molecular motors in neurons: transport mechanisms and roles in brain function, development, and disease. Neuron 68, 610-638. doi: 10.1016/j.neuron.2010.09.039

Hirokawa, N., Pfister, K. K., Yorifuji, H., Wagner, M. C., Brady, S. T., and Bloom, G. S. (1989). Submolecular domains of bovine brain kinesin identified by electron microscopy and monoclonal antibody decoration. Cell 56, 867-878. doi: 10.1016/0092-8674(89)90691-0

Hirokawa, N., Sato-Yoshitake, R., Kobayashi, N., Pfister, K. K., Bloom, G. S., and Brady, S. T. (1991). Kinesin associates with anterogradely transported membranous organelles in vivo. J. Cell Biol. 114, 295-302. doi: 10.1083/jcb.114. 2.295

Hirokawa, N., Sato-Yoshitake, R., Yoshida, T., and Kawashima, T. (1990). Brain dynein (MAP1C) localizes on both anterogradely and retrogradely transported membranous organelles in vivo. J. Cell Biol. 111, 1027-1037. doi: 10.1083/jcb. 111.3.1027

Holt, C. E., Martin, K. C., and Schuman, E. M. (2019). Local translation in neurons: visualization and function. Nat. Struct. Mol. Biol. 26, 557-566. doi: 10.1038/s41594-019-0263-5

Homma, N., Takei, Y., Tanaka, Y., Nakata, T., Terada, S., Kikkawa, M., et al. (2003). Kinesin superfamily protein 2 A (KIF2A) functions in suppression of collateral branch extension. Cell 114, 229-239. doi: 10.1016/s00928674(03)00522-1

Homma, N., Zhou, R., Naseer, M. I., Chaudhary, A. G., Al-Qahtani, M. H., and Hirokawa, N. (2018). KIF2A regulates the development of dentate granule cells and postnatal hippocampal wiring. eLife 7:e30935. doi: 10.7554/eLife. 30935
Hooikaas, P. J., Martin, M., Mühlethaler, T., Kuijntjes, G.-J., Peeters, C. A. E., Katrukha, E. A., et al. (2019). MAP7 family proteins regulate kinesin-1 recruitment and activation. J. Cell Biol. 218, 1298-1318. doi: 10.1083/jcb. 201808065

Horiguchi, K., Hanada, T., Fukui, Y., and Chishti, A. H. (2006). Transport of PIP3 by GAKIN, a kinesin-3 family protein, regulates neuronal cell polarity. J. Cell Biol. 174, 425-436. doi: 10.1083/jcb.200604031

Horiuchi, D., Collins, C. A., Bhat, P., Barkus, R. V., Diantonio, A., and Saxton, W. M. (2007). Control of a kinesin-cargo linkage mechanism by JNK pathway kinases. Curr. Biol. 17, 1313-1317. doi: 10.1016/j.cub.2007.06.062

Howard, J., Hudspeth, A. J., and Vale, R. D. (1989). Movement of microtubules by single kinesin molecules. Nature 342, 154-158. doi: 10.1038/342154a0

Hua, W., Young, E. C., Fleming, M. L., and Gelles, J. (1997). Coupling of kinesin steps to ATP hydrolysis. Nature 388, 390-393. doi: 10.1038/41118

Hüttelmaier, S., Zenklusen, D., Lederer, M., Dictenberg, J., Lorenz, M., Meng, X., et al. (2005). Spatial regulation of $\beta$-actin translation by Src-dependent phosphorylation of ZBP1. Nature 438, 512-515. doi: 10.1038/nature04115

Ikeda, A., Shimada, H., Nishioka, K., Takanashi, M., Hayashida, A., Li, Y., et al. (2019). Clinical heterogeneity of frontotemporal dementia and Parkinsonism linked to chromosome 17 caused by MAPT N279K mutation in relation to tau positron emission tomography features. Mov. Disord. 34, 568-574. doi: $10.1002 / \mathrm{mds} .27623$

Ikuta, J., Maturana, A., Fujita, T., Okajima, T., Tatematsu, K., Tanizawa, K., et al. (2007). Fasciculation and elongation protein zeta-1 (FEZ1) participates in the polarization of hippocampal neuron by controlling the mitochondrial motility. Biochem. Biophys. Res. Commun. 353, 127-132. doi: 10.1016/j.bbrc.2006.11.142

Irobi, J., Holmgren, A., De Winter, V., Asselbergh, B., Gettemans, J., Adriaensen, D., et al. (2012). Mutant HSPB8 causes protein aggregates and a reduced mitochondrial membrane potential in dermal fibroblasts from distal hereditary motor neuropathy patients. Neuromuscul. Disord. 22, 699-711. doi: 10.1016/j.nmd.2012.04.005

Jacquier, A., Delorme, C., Belotti, E., Juntas-Morales, R., Solé, G., Dubourg, O., et al. (2017). Cryptic amyloidogenic elements in mutant NEFH causing Charcot-Marie-Tooth 2 trigger aggresome formation and neuronal death. Acta Neuropathol. Commun. 5:55. doi: 10.1186/s40478-017-0457-1

Jean, S., and Kiger, A. A. (2012). Coordination between RAB GTPase and phosphoinositide regulation and functions. Nat. Rev. Mol. Cell Biol. 13, 463-470. doi: 10.1038/nrm3379

Jennings, S., Chenevert, M., Liu, L., Mottamal, M., Wojcik, E. J., and Huckaba, T. M. (2017). Characterization of kinesin switch I mutations that cause hereditary spastic paraplegia. PLoS One 12:e0180353. doi: 10.1371/journal.pone.0180353

Jordanova, A., De Jonghe, P., Boerkoel, C. F., Takashima, H., De Vriendt, E., Ceuterick, C., et al. (2003). Mutations in the neurofilament light chain gene (NEFL) cause early onset severe Charcot-Marie-Tooth disease. Brain 126, 590-597. doi: 10.1093/brain/awg059

Kanaan, N. M., Hamel, C., Grabinski, T., and Combs, B. (2020). Liquid-liquid phase separation induces pathogenic tau conformations in vitro. Nat. Commun. 11:2809. doi: 10.1038/s41467-020-16580-3

Kanai, Y., Dohmae, N., and Hirokawa, N. (2004). Kinesin transports RNA: isolation and characterization of an RNA-transporting granule. Neuron 43, 513-525. doi: 10.1016/j.neuron.2004.07.022

Kar, A. N., Lee, S. J., and Twiss, J. L. (2018). Expanding axonal transcriptome brings new functions for axonally synthesized proteins in health and disease. Neuroscientist 24, 111-129. doi: 10.1177/1073858417712668

Kellogg, E. H., Hejab, N. M. A., Poepsel, S., Downing, K. H., DiMaio, F., and Nogales, E. (2018). Near-atomic model of microtubule-tau interactions. Science 360, 1242-1246. doi: 10.1126/science.aat 1780

Khalil, B., Morderer, D., Price, P. L., Liu, F., and Rossoll, W. (2018). mRNP assembly, axonal transport, and local translation in neurodegenerative diseases. Brain Res. 1693, 75-91. doi: 10.1016/j.brainres.2018.02.018

Klebe, S., Lossos, A., Azzedine, H., Mundwiller, E., Sheffer, R., Gaussen, M., et al. (2012). KIF1A missense mutations in SPG30, an autosomal recessive spastic paraplegia: distinct phenotypes according to the nature of the mutations. Eur. J. Hum. Genet. 20, 645-649. doi: 10.1038/ejhg.2011.261

Kon, T., Mogami, T., Ohkura, R., Nishiura, M., and Sutoh, K. (2005). ATP hydrolysis cycle-dependent tail motions in cytoplasmic dynein. Nat. Struct. Mol. Biol. 12, 513-519. doi: 10.1038/nsmb930 
Kondo, M., Takei, Y., and Hirokawa, N. (2012). Motor protein KIF1A is essential for hippocampal synaptogenesis and learning enhancement in an enriched environment. Neuron 73, 743-757. doi: 10.1016/j.neuron.2011.12.020

Koppel, I., and Fainzilber, M. (2018). Omics approaches for subcellular translation studies. Mol. Omics 14, 380-388. doi: 10.1039/c8mo00172c

Kornak, U., Mademan, I., Schinke, M., Voigt, M., Krawitz, P., Hecht, J., et al. (2014). Sensory neuropathy with bone destruction due to a mutation in the membrane-shaping atlastin GTPase 3. Brain 137, 683-692. doi: 10.1093/brain/awt357

Krols, M., Asselbergh, B., De Rycke, R., De Winter, V., Seyer, A., Müller, F.J., et al. (2019). Sensory neuropathy-causing mutations in ATL3 affect ER-mitochondria contact sites and impair axonal mitochondrial distribution. Hum. Mol. Genet. 28, 615-627. doi: 10.1093/hmg/ddy352

Kumar, A., Majhi, R. K., Acharya, T. K., Smalla, K.-H., Gundelfinger, E. D., and Goswami, C. (2018). TRPV4 interacts with mitochondrial proteins and acts as a mitochondrial structure-function regulator. bioRxiv [Preprint]. doi: $10.1101 / 330993$

Kural, C., Kim, H., Syed, S., Goshima, G., Gelfand, V. I., and Selvin, P. R. (2005). Kinesin and dynein move a peroxisome in vivo: a tug-of-war or coordinated movement? Science 308, 1469-1472. doi: 10.1126/science.1108408

Lancaster, E., Li, J., Hanania, T., Liem, R., Scheideler, M. A., and Scherer, S. S. (2018). Myelinated axons fail to develop properly in a genetically authentic mouse model of Charcot-Marie-Tooth disease type 2E. Exp. Neurol. 308, 13-25. doi: 10.1016/j.expneurol.2018.06.010

Langlois, S., Tarailo-Graovac, M., Sayson, B., Drögemöller, B., Swenerton, A., Ross, C. J., et al. (2016). De novo dominant variants affecting the motor domain of KIF1A are a cause of PEHO syndrome. Eur. J. Hum. Genet. 24, 949-953. doi: 10.1038/ejhg.2015.217

Lawrence, C. J., Dawe, R. K., Christie, K. R., Cleveland, D. W., Dawson, S. C., Endow, S. A., et al. (2004). A standardized kinesin nomenclature. J. Cell Biol. 167, 19-22. doi: $10.1083 /$ jcb.200408113

Lee, K.-H., Lee, J. S., Lee, D., Seog, D.-H., Lytton, J., Ho, W.-K., et al. (2012). KIF21A-mediated axonal transport and selective endocytosis underlie the polarized targeting of NCKX2. J. Neurosci. 32, 4102-4117. doi: 10.1523/JNEUROSCI.6331-11.2012

Lee, J.-R., Srour, M., Kim, D., Hamdan, F. F., Lim, S.-H., Brunel-Guitton, C., et al. (2015). De novo mutations in the motor domain of KIF1A cause cognitive impairment, spastic paraparesis, axonal neuropathy and cerebellar atrophy. Hum. Mutat. 36, 69-78. doi: 10.1002/humu.22709

Leo, L., Weissmann, C., Burns, M., Kang, M., Song, Y., Qiang, L., et al. (2017). Mutant spastin proteins promote deficits in axonal transport through an isoform-specific mechanism involving casein kinase 2 activation. Hum. Mol. Genet. 26, 2321-2334. doi: 10.1093/hmg/ddx125

Lessard, D. V., Zinder, O. J., Hotta, T., Verhey, K. J., Ohi, R., and Berger, C. L. (2019). Polyglutamylation of tubulin's C-terminal tail controls pausing and motility of kinesin-3 family member KIF1A. J. Biol. Chem. 294, 6353-6363. doi: 10.1074/jbc.RA118.005765

Leung, K.-M., van Horck, F. P., Lin, A. C., Allison, R., Standart, N., and Holt, C. E. (2006). Asymmetrical $\beta$-actin mRNA translation in growth cones mediates attractive turning to netrin-1. Nat. Neurosci. 9, 1247-1256. doi: 10.1038/nn1775

Li, Q., King, S. J., and Xu, J. (2017). Native kinesin-1 does not bind preferentially to GTP-tubulin-rich microtubules in vitro. Cytoskeleton 74, 356-366. doi: $10.1002 / \mathrm{cm} .21386$

Liao, Y.-C., Fernandopulle, M. S., Wang, G., Choi, H., Hao, L., Drerup, C. M., et al. (2019). RNA granules hitchhike on lysosomes for long-distance transport, using annexin A11 as a molecular tether. Cell 179, 147.e20-164.e20. doi: 10.1016/j.cell.2019.08.050

Lin, S., Liu, M., Mozgova, O. I., Yu, W., and Baas, P. W. (2012). Mitotic motors coregulate microtubule patterns in axons and dendrites. J. Neurosci. 32, 14033-14049. doi: 10.1523/JNEUROSCI.3070-12.2012

Lo, K. Y., Kuzmin, A., Unger, S. M., Petersen, J. D., and Silverman, M. A. (2011). KIF1A is the primary anterograde motor protein required for the axonal transport of dense-core vesicles in cultured hippocampal neurons. Neurosci. Lett. 491, 168-173. doi: 10.1016/j.neulet.2011.01.018

Loeffler, T., Schilcher, I., Flunkert, S., and Hutter-Paier, B. (2020). Neurofilamentlight chain as biomarker of neurodegenerative and rare diseases with high translational value. Front. Neurosci. 14:579. doi: 10.3389/fnins.2020. 00579
Lyons, D. A., Naylor, S. G., Scholze, A., and Talbot, W. S. (2009). Kif1b is essential for mRNA localization in oligodendrocytes and development of myelinated axons. Nat. Genet. 41, 854-858. doi: 10.1038/ng.376

Ma, H., Cai, Q., Lu, W., Sheng, Z.-H., and Mochida, S. (2009). KIF5B motor adaptor syntabulin maintains synaptic transmission in sympathetic neurons. J. Neurosci. 29, 13019-13029. doi: 10.1523/JNEUROSCI.2517-09.2009

Maday, S., Twelvetrees, A. E., Moughamian, A. J., and Holzbaur, E. L. F. (2014). Axonal transport: cargo-specific mechanisms of motility and regulation. Neuron 84, 292-309. doi: 10.1016/j.neuron.2014.10.019

Manns, R. P. C., Cook, G. M. W., Holt, C. E., and Keynes, R. J. (2012). Differing semaphorin $3 \mathrm{~A}$ concentrations trigger distinct signaling mechanisms in growth cone collapse. J. Neurosci. 32, 8554-8559. doi: 10.1523/JNEUROSCI.596411.2012

McDermott, C. J., Grierson, A. J., Wood, J. D., Bingley, M., Wharton, S. B., Bushby, K. M. D., et al. (2003). Hereditary spastic paraparesis: disrupted intracellular transport associated with spastin mutation. Ann. Neurol. 54, 748-759. doi: 10.1002/ana.10757

McNeely, K. C., Cupp, T. D., Little, J. N., Janisch, K. M., Shrestha, A., and Dwyer, N. D. (2017). Mutation of Kinesin-6 Kif20b causes defects in cortical neuron polarization and morphogenesis. Neural Dev. 12:5. doi: 10.1186/s13064-017-0082-5

Merianda, T. T., Gomes, C., Yoo, S., Vuppalanchi, D., and Twiss, J. L. (2013). Axonal localization of neuritin/CPG15 mRNA in neuronal populations through distinct 5/ and 3/ UTR elements. J. Neurosci. 33, 13735-13742. doi: 10.1523/JNEUROSCI.0962-13.2013

Midorikawa, R., Takei, Y., and Hirokawa, N. (2006). KIF4 motor regulates activitydependent neuronal survival by suppressing PARP-1 enzymatic activity. Cell 125, 371-383. doi: 10.1016/j.cell.2006.02.039

Miki, H., Setou, M., Kaneshiro, K., and Hirokawa, N. (2001). All kinesin superfamily protein, KIF, genes in mouse and human. Proc. Natl. Acad. Sci. U S A 98, 7004-7011. doi: 10.1073/pnas.111145398

Millecamps, S., Robertson, J., Lariviere, R., Mallet, J., and Julien, J.-P. (2006). Defective axonal transport of neurofilament proteins in neurons overexpressing peripherin. J. Neurochem. 98, 926-938. doi: 10.1111/j.14714159.2006.03932.x

Miller, K. E., DeProto, J., Kaufmann, N., Patel, B. N., Duckworth, A., and Van Vactor, D. (2005). Direct observation demonstrates that Liprin- $\alpha$ is required for trafficking of synaptic vesicles. Curr. Biol. 15, 684-689. doi: 10.1016/j.cub. 2005.02.061

Milovanovic, D., Wu, Y., Bian, X., and De Camilli, P. (2018). A liquid phase of synapsin and lipid vesicles. Science 361, 604-607. doi: 10.1126/science. aat5671

Ming, G., Wong, S. T., Henley, J., Yuan, X., Song, H., Spitzer, N. C., et al. (2002). Adaptation in the chemotactic guidance of nerve growth cones. Nature 417, 411-418. doi: 10.1038/nature745

Misko, A., Jiang, S., Wegorzewska, I., Milbrandt, J., and Baloh, R. H. (2010). Mitofusin 2 is necessary for transport of axonal mitochondria and interacts with the Miro/Milton complex. J. Neurosci. 30, 4232-4240. doi: 10.1523/JNEUROSCI.6248-09.2010

Monroy, B. Y., Sawyer, D. L., Ackermann, B. E., Borden, M. M., Tan, T. C., and McKenney, K. M. (2018). Competition between microtubule-associated proteins directs motor transport. Nat. Commun. 9:1487. doi: 10.1038/s41467018-03909-2

Morfini, G., Quiroga, S., Rosa, A., Kosik, K., and Cáceres, A. (1997). Suppression of KIF2 in PC12 cells alters the distribution of a growth cone nonsynaptic membrane receptor and inhibits neurite extension. J. Cell Biol. 138, 657-669. doi: $10.1083 /$ jcb.138.3.657

Morisaki, T., Lyon, K., DeLuca, K. F., DeLuca, J. G., English, B. P., Zhang, Z., et al. (2016). Real-time quantification of single RNA translation dynamics in living cells. Science 352, 1425-1429. doi: 10.1126/science. aaf0899

Murakami, T., Qamar, S., Lin, J. Q., Schierle, G. S. K., Rees, E., Miyashita, A., et al. (2015). ALS/FTD mutation-induced phase transition of fus liquid droplets and reversible hydrogels into irreversible hydrogels impairs RNP granule function. Neuron 88, 678-690. doi: 10.1016/j.neuron.2015.10.030

Muralidharan, H., and Baas, P. W. (2019). Mitotic motor KIFC1 is an organizer of microtubules in the axon. J. Neurosci. 39, 3792-3811. doi: 10.1523/JNEUROSCI.3099-18.2019 
Nabb, A. T., Frank, M., and Bentley, M. (2020). Smart motors and cargo steering drive kinesin-mediated selective transport. Mol. Cell. Neurosci. 103:103464. doi: 10.1016/j.mcn.2019.103464

Nakajima, K., Yin, X., Takei, Y., Seog, D.-H., Homma, N., and Hirokawa, N. (2012). Molecular motor KIF5A is essential for $\mathrm{GABA}_{A}$ receptor transport and KIF5A deletion causes epilepsy. Neuron 76, 945-961. doi: 10.1016/j.neuron. 2012.10.012

Nakata, T., Niwa, S., Okada, Y., Perez, F., and Hirokawa, N. (2011). Preferential binding of a kinesin-1 motor to GTP-tubulin-rich microtubules underlies polarized vesicle transport. J. Cell Biol. 194, 245-255. doi: 10.1083/jcb. 201104034

Nam, D. E., Yoo, D. H., Choi, S. S., Choi, B.-O., and Chung, K. W. (2018). Wide phenotypic spectrum in axonal Charcot-Marie-Tooth neuropathy type 2 patients with KIF5A mutations. Genes Genomics 40, 77-84. doi: 10.1007/s13258-017-0612-x

Nangaku, M., Sato-Yoshitake, R., Okada, Y., Noda, Y., Takemura, R., Yamazaki, H., et al. (1994). KIF1B, a novel microtubule plus end-directed monomeric motor protein for transport of mitochondria. Cell 79, 1209-1220. doi: 10.1016/0092-8674(94)90012-4

Nédelec, S., Peljto, M., Shi, P., Amoroso, M. W., Kam, L. C., and Wichterle, H. (2012). Concentration-dependent requirement for local protein synthesis in motor neuron subtype-specific response to axon guidance cues. J. Neurosci. 32, 1496-1506. doi: 10.1523/JNEUROSCI.4176-11.2012

Ni, H.-M., Williams, J. A., and Ding, W.-X. (2015). Mitochondrial dynamics and mitochondrial quality control. Redox Biol. 4, 6-13. doi: 10.1016/j.redox.2014. 11.006

Niemann, A., Wagner, K. M., Ruegg, M., and Suter, U. (2009). GDAP1 mutations differ in their effects on mitochondrial dynamics and apoptosis depending on the mode of inheritance. Neurobiol. Dis. 36, 509-520. doi: 10.1016/j.nbd.2009. 09.011

Nishimura, T., Kato, K., Yamaguchi, T., Fukata, Y., Ohno, S., and Kaibuchi, K. (2004). Role of the PAR-3-KIF3 complex in the establishment of neuronal polarity. Nat. Cell Biol. 6, 328-334. doi: 10.1038/ncb1118

Nishimura, A. L., Mitne-Neto, M., Silva, H. C. A., Richieri-Costa, A., Middleton, S., Cascio, D., et al. (2004). A mutation in the vesicle-trafficking protein VAPB causes late-onset spinal muscular atrophy and amyotrophic lateral sclerosis. Am. J. Hum. Genet. 75, 822-831. doi: 10.1086/425287

Niwa, S., Tanaka, Y., and Hirokawa, N. (2008). KIF1B $\beta$ - and KIF1Amediated axonal transport of presynaptic regulator Rab3 occurs in a GTP-dependent manner through DENN/MADD. Nat. Cell Biol. 10, 1269-1279. doi: $10.1038 /$ ncb 1785

Nötzel, M., Rosso, G., Möllmert, S., Seifert, A., Schlüßler, R., Kim, K., et al. (2018). Axonal transport, phase-separated compartments and neuron mechanics-a new approach to investigate neurodegenerative diseases. Front. Cell. Neurosci. 12:358. doi: 10.3389/fncel.2018.00358

Oberstadt, M., Claßen, J., Arendt, T., and Holzer, M. (2018). TDP43 and cytoskeletal proteins in ALS. Mol. Neurobiol. 55, 3143-3151. doi: 10.1007/s12035-017-0543-1

Okada, Y., and Hirokawa, N. (2000). Mechanism of the single-headed processivity: diffusional anchoring between the K-loop of kinesin and the $\mathrm{C}$ terminus of tubulin. Proc. Natl. Acad. Sci. U S A 97, 640-645. doi: 10.1073/pnas.97.2.640

Okada, Y., Yamazaki, H., Sekine-Aizawa, Y., and Hirokawa, N. (1995). The neuron-specific kinesin superfamily protein KIF1A is a unique monomeric motor for anterograde axonal transport of synaptic vesicle precursors. Cell 81, 769-780. doi: 10.1016/0092-8674(95)90538-3

Olenick, M. A., and Holzbaur, E. L. F. (2019). Dynein activators and adaptors at a glance. J. Cell Sci. 132:jcs227132. doi: 10.1242/jcs.227132

Pan, X., Cao, Y., Stucchi, R., Hooikaas, P. J., Portegies, S., Will, L., et al. (2019). MAP7D2 localizes to the proximal axon and locally promotes kinesin1-mediated cargo transport into the axon. Cell Rep. 26, 1988.e6-1999.e6. doi: 10.1016/j.celrep.2019.01.084

Park, S. M., Littleton, J. T., Park, H. R., and Lee, J. H. (2016). Drosophila homolog of human KIF22 at the autism-linked 16p11.2 Loci influences synaptic connectivity at larval neuromuscular junctions. Exp. Neurobiol. 25, 33-39. doi: 10.5607/en.2016.25.1.33

Paschal, B. M., Shpetner, H. S., and Vallee, R. B. (1987). MAP 1C is a microtubuleactivated ATPase which translocates microtubules in vitro and has dynein-like properties. J. Cell Biol. 105, 1273-1282. doi: 10.1083/jcb.105.3.1273
Paschal, B. M., and Vallee, R. B. (1987). Retrograde transport by the microtubuleassociated protein MAP 1C. Nature 330, 181-183. doi: 10.1038/330181a0

Patel, A., Lee, H. O., Jawerth, L., Maharana, S., Jahnel, M., Hein, M. Y., et al. (2015). A liquid-to-solid phase transition of the ALS protein FUS accelerated by disease mutation. Cell 162, 1066-1077. doi: 10.1016/j.cell.2015.07.047

Perlson, E., Hanz, S., Ben-Yaakov, K., Segal-Ruder, Y., Seger, R., and Fainzilber, M. (2005). Vimentin-dependent spatial translocation of an activated MAP kinase in injured nerve. Neuron 45, 715-726. doi: 10.1016/j.neuron.2005.01.023

Perry, R. B.-T., Doron-Mandel, E., Iavnilovitch, E., Rishal, I., Dagan, S. Y., Tsoory, M., et al. (2012). Subcellular knockout of importin $\beta 1$ perturbs axonal retrograde signaling. Neuron 75, 294-305. doi: 10.1016/j.neuron.2012.05.033

Peskett, T. R., Rau, F., O’Driscoll, J., Patani, R., Lowe, A. R., and Saibil, H. R. (2018). A liquid to solid phase transition underlying pathological huntingtin exon1 aggregation. Mol. Cell 70, 588.e6-601.e6. doi: 10.1016/j.molcel.2018. 04.007

Pfenninger, K. H., Laurino, L., Peretti, D., Wang, X., Rosso, S., Morfini, G., et al. (2003). Regulation of membrane expansion at the nerve growth cone. J. Cell. Sci. 116, 1209-1217. doi: 10.1242/jcs.00285

Prasad, A., Bharathi, V., Sivalingam, V., Girdhar, A., and Patel, B. K. (2019). Molecular mechanisms of TDP-43 misfolding and pathology in amyotrophic lateral sclerosis. Front. Mol. Neurosci. 12:25. doi: 10.3389/fnmol.2019.00025

Pushpalatha, K. V., and Besse, F. (2019). Local translation in axons: when membraneless RNP granules meet membrane-bound organelles. Front. Mol. Biosci. 6:129. doi: 10.3389/fmolb.2019.00129

Rao, M. V., Mohan, P. S., Kumar, A., Yuan, A., Montagna, L., Campbell, J., et al. (2011). The myosin Va head domain binds to the neurofilament-L rod and modulates endoplasmic reticulum (ER) content and distribution within axons. PLoS One 6:e17087. doi: 10.1371/journal.pone.0017087

Rebelo, A. P., Abrams, A. J., Cottenie, E., Horga, A., Gonzalez, M., Bis, D. M., et al. (2016). Cryptic amyloidogenic elements in the $3^{\prime}$ UTRs of neurofilament genes trigger axonal neuropathy. Am. J. Hum. Genet. 98, 597-614. doi: 10.1016/j.ajhg. 2016.02.022

Reck-Peterson, S. L., Redwine, W. B., Vale, R. D., and Carter, A. P. (2018). The cytoplasmic dynein transport machinery and its many cargoes. Nat. Rev. Mol. Cell Biol. 19:382. doi: 10.1038/s41580-018-0021-2

Rishal, I., and Fainzilber, M. (2014). Axon-soma communication in neuronal injury. Nat. Rev. Neurosci. 15, 32-42. doi: 10.1038/nrn3609

Rivière, J.-B., Ramalingam, S., Lavastre, V., Shekarabi, M., Holbert, S., Lafontaine, J., et al. (2011). KIF1A, an axonal transporter of synaptic vesicles, is mutated in hereditary sensory and autonomic neuropathy type 2. Am. J. Hum. Genet. 89, 219-230. doi: 10.1016/j.ajhg.2011.06.013

Roll-Mecak, A., and Vale, R. D. (2008). Structural basis of microtubule severing by the hereditary spastic paraplegia protein spastin. Nature 451, 363-367. doi: 10.1038/nature06482

Rotem, N., Magen, I., Ionescu, A., Gershoni-Emek, N., Altman, T., Costa, C. J., et al. (2017). ALS along the axons-expression of coding and noncoding RNA differs in axons of ALS models. Sci. Rep. 7:44500. doi: 10.1038/srep44500

Saal, L., Briese, M., Kneitz, S., Glinka, M., and Sendtner, M. (2014). Subcellular transcriptome alterations in a cell culture model of spinal muscular atrophy point to widespread defects in axonal growth and presynaptic differentiation. RNA 20, 1789-1802. doi: 10.1261/rna.047373.114

Sahoo, P. K., Lee, S. J., Jaiswal, P. B., Alber, S., Kar, A. N., Miller-Randolph, S., et al. (2018a). Axonal G3BP1 stress granule protein limits axonal mRNA translation and nerve regeneration. Nat. Commun. 9:3358. doi: 10.1038/s41467-01805647-x

Sahoo, P. K., Smith, D. S., Perrone-Bizzozero, N., and Twiss, J. L. (2018b). Axonal mRNA transport and translation at a glance. J. Cell Sci. 131:jcs196808. doi: $10.1242 /$ jcs. 196808

Sainio, M. T., Ylikallio, E., Mäenpää, L., Lahtela, J., Mattila, P., Auranen, M., et al. (2018). Absence of NEFL in patient-specific neurons in early-onset charcot-marie-tooth neuropathy. Neurol. Genet. 4:e244. doi: 10.1212/nxg. 0000000000000244

Salinas, S., Carazo-Salas, R. E., Proukakis, C., Schiavo, G., and Warner, T. T. (2007). Spastin and microtubules: functions in health and disease. J. Neurosci. Res. 85, 2778-2782. doi: 10.1002/jnr.21238

Samanta, D., and Gokden, M. (2019). PEHO syndrome: KIF1A mutation and decreased activity of mitochondrial respiratory chain complex. J. Clin. Neurosci. 61, 298-301. doi: 10.1016/j.jocn.2018.10.091 
Sapir, T., Levy, T., Sakakibara, A., Rabinkov, A., Miyata, T., and Reiner, O. (2013). Shootin 1 acts in concert with KIF20B to promote polarization of migrating neurons. J. Neurosci. 33, 11932-11948. doi: 10.1523/jneurosci.542512.2013

Saxton, W. M., and Hollenbeck, P. J. (2012). The axonal transport of mitochondria. J. Cell. Sci. 125, 2095-2104. doi: 10.1242/jcs.053850

Schiavo, G., Greensmith, L., Hafezparast, M., and Fisher, E. M. C. (2013). Cytoplasmic dynein heavy chain: the servant of many masters. Trends Neurosci. 36, 641-651. doi: 10.1016/j.tins.2013.08.001

Schnitzer, M. J., and Block, S. M. (1997). Kinesin hydrolyses one ATP per 8-nm step. Nature 388, 386-390. doi: 10.1038/41111

Sekine, Y., Okada, Y., Noda, Y., Kondo, S., Aizawa, H., Takemura, R., et al. (1994). A novel microtubule-based motor protein (KIF4) for organelle transports, whose expression is regulated developmentally. J. Cell Biol. 127, 187-201. doi: $10.1083 /$ jcb.127.1.187

Setou, M., Seog, D.-H., Tanaka, Y., Kanai, Y., Takei, Y., Kawagishi, M., et al. (2002). Glutamate-receptor-interacting protein GRIP1 directly steers kinesin to dendrites. Nature 417, 83-87. doi: 10.1038/nature743

Shribman, S., Reid, E., Crosby, A. H., Houlden, H., and Warner, T. T. (2019). Hereditary spastic paraplegia: from diagnosis to emerging therapeutic approaches. Lancet Neurol. 18, 1136-1146. doi: 10.1016/S1474-4422(19) 30235-2

Siuda, J., Fujioka, S., and Wszolek, Z. K. (2014). Parkinsonian syndrome in familial frontotemporal dementia. Parkinsonism Relat. Disord. 20, 957-964. doi: 10.1016/j.parkreldis.2014.06.004

Sleigh, J. N., Dawes, J. M., West, S. J., Wei, N., Spaulding, E. L., Gómez-Martín, A., et al. (2017a). Trk receptor signaling and sensory neuron fate are perturbed in human neuropathy caused by Gars mutations. Proc. Natl. Acad. Sci. U S A 114, E3324-E3333. doi: 10.1073/pnas.1614557114

Sleigh, J. N., Gómez-Martín, A., Wei, N., Bai, G., Yang, X.-L., and Schiavo, G. (2017b). Neuropilin 1 sequestration by neuropathogenic mutant glycyl-tRNA synthetase is permissive to vascular homeostasis. Sci. Rep. 7:9216. doi: 10.1038/s41598-017-10005-w

Sleigh, J. N., Rossor, A. M., Fellows, A. D., Tosolini, A. P., and Schiavo, G. (2019). Axonal transport and neurological disease. Nat. Rev. Neurol. 15, 691-703. doi: 10.1038/s41582-019-0257-2

Smith, B. N., Ticozzi, N., Fallini, C., Gkazi, A. S., Topp, S., Kenna, K. P., et al. (2014). Exome-wide rare variant analysis identifies TUBA4A mutations associated with familial ALS. Neuron 84, 324-331. doi: 10.1016/j.neuron.2014. 09.027

Solowska, J. M., Morfini, G., Falnikar, A., Himes, B. T., Brady, S. T., Huang, D., et al. (2008). Quantitative and functional analyses of spastin in the nervous system: implications for hereditary spastic paraplegia. J. Neurosci. 28, 2147-2157. doi: 10.1523/jneurosci.3159-07.2008

Soppina, V., and Verhey, K. J. (2014). The family-specific K-loop influences the microtubule on-rate but not the superprocessivity of kinesin-3 motors. Mol. Biol. Cell 25, 2161-2170. doi: 10.1091/mbc.e14-01-0696

Sorra, K. E., Mishra, A., Kirov, S. A., and Harris, K. M. (2006). Dense core vesicles resemble active-zone transport vesicles and are diminished following synaptogenesis in mature hippocampal slices. Neuroscience 141, 2097-2106. doi: 10.1016/j.neuroscience.2006.05.033

Spaulding, E. L., Sleigh, J. N., Morelli, K. H., Pinter, M. J., Burgess, R. W., and Seburn, K. L. (2016). Synaptic deficits at neuromuscular junctions in two mouse models of charcot-marie-tooth type 2d. J. Neurosci. 36, 3254-3267. doi: 10.1523/jneurosci.1762-15.2016

Staras, K., Branco, T., Burden, J. J., Pozo, K., Darcy, K., Marra, V., et al. (2010). A vesicle superpool spans multiple presynaptic terminals in hippocampal neurons. Neuron 66, 37-44. doi: 10.1016/j.neuron.2010.03.020

Storkebaum, E., Leitão-Gonçalves, R., Godenschwege, T., Nangle, L., Mejia, M., Bosmans, I., et al. (2009). Dominant mutations in the tyrosyl-tRNA synthetase gene recapitulate in Drosophila features of human Charcot-Marie-Tooth neuropathy. Proc. Natl. Acad. Sci. U S A 106, 11782-11787. doi: 10.1073/pnas. 0905339106

Stucchi, R., Plucińska, G., Hummel, J. J. A., Zahavi, E. E., Guerra San Juan, I., Klykov, O., et al. (2018). Regulation of KIF1A-driven dense core vesicle transport: $\mathrm{Ca}^{2+} / \mathrm{CaM}$ controls DCV binding and liprin- $\alpha /$ TANC2 recruits DCVs to postsynaptic sites. Cell Rep. 24, 685-700. doi: 10.1016/j.celrep.2018. 06.071
Stum, M., McLaughlin, H. M., Kleinbrink, E. L., Miers, K. E., Ackerman, S. L., Seburn, K. L., et al. (2011). An assessment of mechanisms underlying peripheral axonal degeneration caused by aminoacyl-tRNA synthetase mutations. Mol. Cell. Neurosci. 46, 432-443. doi: 10.1016/j.mcn.2010.11.006

Su, Y.-Y., Ye, M., Li, L., Liu, C., Pan, J., Liu, W.-W., et al. (2013). KIF5B promotes the forward transport and axonal function of the voltage-gated sodium channel Nav1.8. J. Neurosci. 33, 17884-17896. doi: 10.1523/jneurosci.0539-13.2013

Südhof, T. C. (2018). Towards an understanding of synapse formation. Neuron 100, 276-293. doi: 10.1016/j.neuron.2018.09.040

Swarnkar, S., Avchalumov, Y., Raveendra, B. L., Grinman, E., and Puthanveettil, S. V. (2018). Kinesin family of proteins Kif11 and Kif21B act as inhibitory constraints of excitatory synaptic transmission through distinct mechanisms. Sci. Rep. 8:17419. doi: 10.1038/s41598-018-35634-7

Sweeney, H. L., and Holzbaur, E. L. F. (2018). Motor proteins. Cold Spring Harb. Perspect. Biol. 10:a021931. doi: 10.1101/cshperspect.a021931

Takeda, S., Yamazaki, H., Seog, D. H., Kanai, Y., Terada, S., and Hirokawa, N. (2000). Kinesin superfamily protein 3 (KIF3) motor transports fodrinassociating vesicles important for neurite building. J. Cell Biol. 148, 1255-1265. doi: $10.1083 /$ jcb.148.6.1255

Tanaka, K., Sugiura, Y., Ichishita, R., Mihara, K., and Oka, T. (2011). KLP6: a newly identified kinesin that regulates the morphology and transport of mitochondria in neuronal cells. J. Cell Sci. 124, 2457-2465. doi: 10.1242/jcs.086470

Tao, C.-L., Liu, Y.-T., Zhou, Z. H., Lau, P.-M., and Bi, G.-Q. (2018). Accumulation of dense core vesicles in hippocampal synapses following chronic inactivity. Front. Neuroanat. 12:48. doi: 10.3389/fnana.2018.00048

Tarrade, A., Fassier, C., Courageot, S., Charvin, D., Vitte, J., Peris, L., et al. (2006). A mutation of spastin is responsible for swellings and impairment of transport in a region of axon characterized by changes in microtubule composition. Hum. Mol. Genet. 15, 3544-3558. doi: 10.1093/hmg/ddl431

Taylor, M. P., and Enquist, L. W. (2015). Axonal spread of neuroinvasive viral infections. Trends Microbiol. 23, 283-288. doi: 10.1016/j.tim.2015.01.002

Terenzio, M., Koley, S., Samra, N., Rishal, I., Zhao, Q., Sahoo, P. K., et al. (2018). Locally translated mTOR controls axonal local translation in nerve injury. Science 359, 1416-1421. doi: 10.1126/science.aan1053

Tomkins, J., Usher, P., Slade, J. Y., Ince, P. G., Curtis, A., Bushby, K., et al. (1998). Novel insertion in the KSP region of the neurofilament heavy gene in amyotrophic lateral sclerosis (ALS). Neuroreport 9, 3967-3970. doi: 10.1097/00001756-199812010-00036

Tsang, B., Arsenault, J., Vernon, R. M., Lin, H., Sonenberg, N., Wang, L.-Y., et al. (2019). Phosphoregulated FMRP phase separation models activity-dependent translation through bidirectional control of mRNA granule formation. Proc. Natl. Acad. Sci. US A 116, 4218-4227. doi: 10.1073/pnas.1814385116

Tushev, G., Glock, C., Heumüller, M., Biever, A., Jovanovic, M., and Schuman, E. M. (2018). Alternative 3' UTRs modify the localization, regulatory potential, stability, and plasticity of mRNAs in neuronal compartments. Neuron 98, 495.e6-511.e6. doi: 10.1016/j.neuron.2018.03.030

Vale, R. D., Reese, T. S., and Sheetz, M. P. (1985). Identification of a novel forcegenerating protein, kinesin, involved in microtubule-based motility. Cell 42 , 39-50. doi: 10.1016/s0092-8674(85)80099-4

van der Vaart, B., van Riel, W. E., Doodhi, H., Kevenaar, J. T., Katrukha, E. A., Gumy, L., et al. (2013). CFEOM1-associated kinesin KIF21A is a cortical microtubule growth inhibitor. Dev. Cell 27, 145-160. doi: 10.1016/j.devcel. 2013.09.010

Verhey, K. J., and Hammond, J. W. (2009). Traffic control: regulation of kinesin motors. Nat. Rev. Mol. Cell Biol. 10, 765-777. doi: 10.1038/ nrm2782

Verhey, K. J., Meyer, D., Deehan, R., Blenis, J., Schnapp, B. J., Rapoport, T. A., et al. (2001). Cargo of kinesin identified as JIP scaffolding proteins and associated signaling molecules. J. Cell Biol. 152, 959-970. doi: 10.1083/jcb.152.5.959

Verhoeven, K., Claeys, K. G., Züchner, S., Schröder, J. M., Weis, J., Ceuterick, C., et al. (2006). MFN2 mutation distribution and genotype/phenotype correlation in Charcot-Marie-Tooth type 2. Brain 129, 2093-2102. doi: 10.1093/brain/awl126

Volkening, K., Leystra-Lantz, C., Yang, W., Jaffee, H., and Strong, M. J. (2009). Tar DNA binding protein of $43 \mathrm{kDa}$ (TDP-43), 14-3-3 proteins and copper/zinc superoxide dismutase (SOD1) interact to modulate NFL mRNA stability. Implications for altered RNA processing in amyotrophic lateral sclerosis (ALS). Brain Res. 1305, 168-182. doi: 10.1016/j.brainres.2009.09.105 
Vukoja, A., Rey, U., Petzoldt, A. G., Ott, C., Vollweiter, D., Quentin, C., et al. (2018). Presynaptic biogenesis requires axonal transport of lysosome-related vesicles. Neuron 99, 1216.e7-1232.e7. doi: 10.1016/j.neuron.2018.08.004

Wang, W., Cao, L., Wang, C., Gigant, B., and Knossow, M. (2015). Kinesin, 30 years later: recent insights from structural studies. Protein Sci. 24, 1047-1056. doi: 10.1002/pro.2697

Wang, X., and Schwarz, T. L. (2009). The mechanism of $\mathrm{Ca}^{2+}$-dependent regulation of kinesin-mediated mitochondrial motility. Cell 136, 163-174. doi: 10.1016/j.cell.2008.11.046

Wang, L., Tanaka, Y., Wang, D., Morikawa, M., Zhou, R., Homma, N., et al. (2018). The atypical kinesin KIF26A facilitates termination of nociceptive responses by sequestering focal adhesion kinase. Cell Rep. 24, 2894-2907. doi: 10.1016/j. celrep.2018.05.075

Wegmann, S., Eftekharzadeh, B., Tepper, K., Zoltowska, K. M., Bennett, R. E., Dujardin, S., et al. (2018). Tau protein liquid-liquid phase separation can initiate tau aggregation. EMBO J. 37:e98049. doi: 10.15252/embj.2017 98049

Weisenberg, R. C. (1972). Microtubule formation in vitro in solutions containing low calcium concentrations. Science 177, 1104-1105. doi: 10.1126/science.177. 4054.1104

Welshhans, K., and Bassell, G. J. (2011). Netrin-1-induced local $\beta$-actin synthesis and growth cone guidance requires zipcode binding protein 1. J. Neurosci. 31, 9800-9813. doi: 10.1523/JNEUROSCI.0166-11.2011

Willis, D., Li, K. W., Zheng, J.-Q., Chang, J. H., Smit, A. B., Smit, A., et al. (2005). Differential transport and local translation of cytoskeletal, injury-response and neurodegeneration protein mRNAs in axons. J. Neurosci. 25, 778-791. doi: 10.1523/jneurosci.4235-04.2005

Woehlke, G., Ruby, A. K., Hart, C. L., Ly, B., Hom-Booher, N., and Vale, R. D. (1997). Microtubule interaction site of the kinesin motor. Cell 90, 207-216. doi: 10.1016/s0092-8674(00)80329-3

Wozniak, M. J., Melzer, M., Dorner, C., Haring, H.-U., and Lammers, R. (2005). The novel protein KBP regulates mitochondria localization by interaction with a kinesin-like protein. BMC Cell Biol. 6:35. doi: 10.1186/1471-2121-6-35

Wu, X., Cai, Q., Shen, Z., Chen, X., Zeng, M., Du, S., et al. (2019). RIM and RIM-BP Form presynaptic active-zone-like condensates via phase separation. Mol. Cell 73, 971.e5-984.e5. doi: 10.1016/j.molcel.2018.12.007

Wu, B., Eliscovich, C., Yoon, Y. J., and Singer, R. H. (2016). Translation dynamics of single mRNAs in live cells and neurons. Science 352, 1430-1435. doi: 10.1126/science.aaf1084

Xia, C.-H., Roberts, E. A., Her, L.-S., Liu, X., Williams, D. S., Cleveland, D. W., et al. (2003). Abnormal neurofilament transport caused by targeted disruption of neuronal kinesin heavy chain KIF5A. J. Cell Biol. 161, 55-66. doi: 10.1083/jcb. 200301026

Xiao, Q., Hu, X., Wei, Z., and Tam, K. Y. (2016). Cytoskeleton molecular motors: structures and their functions in neuron. Int. J. Biol. Sci. 12, 1083-1092. doi: $10.7150 /$ ijbs. 15633

Xie, W., Nangle, L. A., Zhang, W., Schimmel, P., and Yang, X.-L. (2007). Longrange structural effects of a Charcot-Marie-Tooth disease-causing mutation in human glycyl-tRNA synthetase. Proc. Natl. Acad. Sci. U S A 104, 9976-9981. doi: 10.1073/pnas.0703908104

Xu, F., Takahashi, H., Tanaka, Y., Ichinose, S., Niwa, S., Wicklund, M. P., et al. (2018). KIF1B $\beta$ mutations detected in hereditary neuropathy impair IGF1R transport and axon growth. J. Cell Biol. 217, 3480-3496. doi: 10.1083/jcb. 201801085
Yalçın, B., Zhao, L., Stofanko, M., O’Sullivan, N. C., Kang, Z. H., Roost, A., et al. (2017). Modeling of axonal endoplasmic reticulum network by spastic paraplegia proteins. eLife 6:e23882. doi: 10.7554/elife.23882

Yao, J., Sasaki, Y., Wen, Z., Bassell, G. J., and Zheng, J. Q. (2006). An essential role for $\beta$-actin mRNA localization and translation in $\mathrm{Ca}^{2+}$-dependent growth cone guidance. Nat. Neurosci. 9, 1265-1273. doi: 10.1038/nn1773

Yates, D. M., Manser, C., De Vos, K. J., Shaw, C. E., McLoughlin, D. M., and Miller, C. C. J. (2009). Neurofilament subunit (NFL) head domain phosphorylation regulates axonal transport of neurofilaments. Eur. J. Cell Biol. 88, 193-202. doi: 10.1016/j.ejcb.2008.11.004

Ylikallio, E., Kim, D., Isohanni, P., Auranen, M., Kim, E., Lönnqvist, T., et al. (2015). Dominant transmission of de novo KIF1A motor domain variant underlying pure spastic paraplegia. Eur. J. Hum. Genet. 23, 1427-1430. doi: 10.1038/ejhg.2014.297

Yonekawa, Y., Harada, A., Okada, Y., Funakoshi, T., Kanai, Y., Takei, Y., et al. (1998). Defect in synaptic vesicle precursor transport and neuronal cell death in KIF1A motor protein-deficient mice. J. Cell Biol. 141, 431-441. doi: $10.1083 /$ jcb.141.2.431

Yoshimura, Y., Terabayashi, T., and Miki, H. (2010). Par1b/MARK2 phosphorylates kinesin-like motor protein GAKIN/KIF13B to regulate axon formation. Mol. Cell. Biol. 30, 2206-2219. doi: 10.1128/mcb. 01181-09

Yudin, D., Hanz, S., Yoo, S., Iavnilovitch, E., Willis, D., Gradus, T., et al. (2008). Localized regulation of axonal RanGTPase controls retrograde injury signaling in peripheral nerve. Neuron 59, 241-252. doi: 10.1016/j.neuron.2008.05.029

Zhang, H. L., Eom, T., Oleynikov, Y., Shenoy, S. M., Liebelt, D. A., Dictenberg, J. B., et al. (2001). Neurotrophin-induced transport of a $\beta$-actin mRNP complex increases $\beta$-actin levels and stimulates growth cone motility. Neuron 31, 261-275. doi: 10.1016/s0896-6273(01)00357-9

Zhang, Y. V., Hannan, S. B., Kern, J. V., Stanchev, D. T., Koç, B., Jahn, T. R., et al. (2017). The KIF1A homolog Unc-104 is important for spontaneous release, postsynaptic density maturation and perisynaptic scaffold organization. Sci. Rep. 7:38172. doi: 10.1038/srep38172

Zhao, C., Takita, J., Tanaka, Y., Setou, M., Nakagawa, T., Takeda, S., et al. (2001). Charcot-Marie-Tooth disease type $2 \mathrm{~A}$ caused by mutation in a microtubule motor KIF1Bß. Cell 105, 587-597. doi: 10.1016/s0092-8674(01)00363-4

Zhou, R., Niwa, S., Homma, N., Takei, Y., and Hirokawa, N. (2009). KIF26A is an unconventional kinesin and regulates GDNF-ret signaling in enteric neuronal development. Cell 139, 802-813. doi: 10.1016/j.cell.2009.10.023

Züchner, S., and Vance, J. M. (2006). Mechanisms of disease: a molecular genetic update on hereditary axonal neuropathies. Nat. Clin. Pract. Neurol. 2, 45-53. doi: 10.1038/ncpneuro0071

Conflict of Interest: The authors declare that the research was conducted in the absence of any commercial or financial relationships that could be construed as a potential conflict of interest.

Copyright (C) 2020 Guillaud, El-Agamy, Otsuki and Terenzio. This is an open-access article distributed under the terms of the Creative Commons Attribution License (CC BY). The use, distribution or reproduction in other forums is permitted, provided the original author(s) and the copyright owner(s) are credited and that the original publication in this journal is cited, in accordance with accepted academic practice. No use, distribution or reproduction is permitted which does not comply with these terms. 